\title{
Ambient geochemical baselines for trace elements in Chernozems - approximation of geochemical soil transformation in an agricultural area
}

\author{
Labaz Beata • Kabala Cezary • Waroszewski Jaroslaw
}

Received: 1 August 2018 / Accepted: 26 November 2018 /Published online: 15 December 2018

(C) The Author(s) 2018

\begin{abstract}
The legal regulatory/action levels of trace elements in soils are established at high concentrations, at which the crucial functions of soil are at risk or are eliminated. However, concentrations below these action levels, but above presumed natural levels, may also limit particular ecosystem services, including organic food production. Thus, defining the (ambient) background concentrations is an essential part of environmental or health risk assessment, e.g., on Chernozems, which are considered to be the most productive soils and ones that should be protected against all forms of contamination. Based on 28 profiles of chernozemic soils developed from loess in an agricultural region of SW Poland presumed to be free of industrial contamination, ambient geochemical baselines have been derived for $\mathrm{Fe}$ and six trace metals for four standardized soil layers, including the topsoil (plow layer) and parent material layers. The median values for the plow layer $(1.89 \%$ for $\mathrm{Fe}$, and 537, 49, 17, 14, and $26 \mathrm{mg} \mathrm{kg}^{-1}$ for $\mathrm{Mn}, \mathrm{Zn}, \mathrm{Pb}, \mathrm{Cu}$, and $\mathrm{Ni}$, respectively) are lower than the values reported for other Chernozems in SE Poland/Europe/the world, and thus may serve as a general geochemical baseline for chernozemic soils developed from loess. The concentration of $\mathrm{Cd}$, although lower than in other Chernozems around the world, is higher than in Ukrainian
\end{abstract}

L. Beata $(\bowtie) \cdot$ K. Cezary $\cdot$ W. Jaroslaw

Wrocław University of Environmental and Life Sciences, Institute of Soil Science and Environmental Protection, Grunwaldzka 53, 50-357 Wrocław, Poland

e-mail: beata.labaz@upwr.edu.pl
Chernozems and thus may serve as a local (or Central European) baseline only. The median concentrations of $\mathrm{Fe}, \mathrm{Cu}, \mathrm{Mn}$, and $\mathrm{Zn}$ are very close to their concentrations in the Chernozem buried under the Neolithic kurgan. However, $\mathrm{Pb}$ and $\mathrm{Cd}$ concentrations are two times higher than in the buried soil, indicating the scale of general contamination of the topsoil horizons of arable soils. Concentrations of the elements under study, excluding $\mathrm{Fe}$, in both the buried and surface soils are significantly higher in the topsoil layer compared to parent material (loess), and this justifies the separate baseline values for topsoil horizons, instead of background values derived universally for parent rock types. This is essential, in particular in soils texturally differentiated within profiles, where the subsoil material has a different origin and cannot be considered the parent material for topsoil horizons. Underlying or locally outcropped bedrock (e.g., serpentinite rocks) may naturally enhance the total concentration of trace elements in the entire soil profile by the addition of metal-rich regolith particles during the formation of surface covers, e.g., by eolian processes under periglacial conditions (Late Pleistocene). Such soils are naturally enriched with metals (with nickel in the case of serpentinite bedrock), cannot be considered contaminated, and thus require a separate legal treatment, including separate (or individually suited) background baselines for health risk assessments.

Keywords Chernozems - Loess - Trace elements · Ambient background - Geochemical baseline $\cdot$ Risk assessment 


\section{Introduction}

The content of trace elements in soil arouses great interest among farmers, ecologists, and biologists because soil, as an important medium for the circulation of elements in the environment, has a significant impact on the chemical composition of plants and therefore on the quality of food (Adriano 2001; Kabata-Pendias 2004; Karak et al. 2017). Many elements (e.g., $\mathrm{Co}, \mathrm{Cr}, \mathrm{Cu}, \mathrm{Fe}$, $\mathrm{Mn}, \mathrm{Ni}$, and $\mathrm{Zn}$ ) are essential for plants as micronutrients or components of enzymes important in metabolic processes, nitrogen assimilation, transport through biological membranes, or the regulation of osmotic pressure in cells (Bruins et al. 2000; Hansda and Kumar 2017). For other elements (e.g., Cd, Hg, Pb, Au, $\mathrm{Ag}$ ), no beneficial biological functions are recognized, or it has been found, on the contrary, that even small amounts of these disrupt biochemical processes and therefore are potentially toxic for living organisms (Pan et al. 2010; Seregin and Ivanov 2001; Kajka and Rutkowska 2018). Toxic impacts can also stem from these elements (Vodyanitskii 2013).

The amount of trace elements in soils is the result of their content derived from natural sources as well as from human activities (Alloway 2013). Among the natural factors, the key factor is the parent rock and those conditions which affect the intensity of rock weathering (Bonifacio et al. 2010; Orzechowski and Smólczynski 2010; Kierczak et al. 2016). In turn, anthropogenic influences can be direct, as in the intentional supply of elements along with mineral or organic fertilizers (Borui et al. 2017; Kabala et al. 2011; Schaecke et al. 2002), or indirect, as in fallout from metal-bearing airborne dust from industrial emissions (Ghayoraneh and Qishlaqi 2017; Komorowski and Szulc 2017; Kowalska et al. 2016). In heavily urbanized or industrial areas, the quantities of trace elements originating from anthropogenic sources can exceed the quantities originating from natural sources (Cannon and Horton 2009; Cheng et al. 2015; Wcisło et al. 2002; Tyszka et al. 2016).

The regulatory levels of trace elements (and other xenobiotics) have been approximated in most countries (Dung et al. 2013; Maliszewska-Kordybach and Smreczak 2003; Kabala et al. 2013; Mehr et al. 2017; Reimann and Garrett 2005). Metal levels have been differently defined and termed (e.g., action levels or maximum admissible concentration values), but, in general, the confirmation of metal content increases above those levels always results in the commencement of administrative procedures aimed at reducing the environmental or health risks (Karczewska and Kabala 2017; US EPA Interstate Technology and Regulatory Council 2008). Regulatory/action levels are established at a high metal concentration, one at which the crucial functions of soil are at risk or are eliminated, including food production, water filtration, and contaminant buffering (Ghayoraneh and Qishlaqi 2017; MedynskaJuraszek and Kabala 2012). A metal concentration in soil at the action level indicates an extreme state; however, various levels of soil contamination may occur that do not totally eliminate food production, but may limit particular soil/ecosystem services to various extents. In particular, "high quality food production" may require the best soil quality, including a "lack of soil contamination" with trace metals (Reganold and Wachter 2016), and this prompts the question as to the "natural," "normal," or "background" concentrations of metals in soils.

Originally, the term "geochemical background" was developed for exploration geochemistry and it was defined as a "normal" abundance of an element in rocks and barren earth materials. Any "anomalies," i.e., a metal concentration that exceeds its "normal" concentration, have significant importance in the selection of sites for further exploration and potential metal ore exploitation (Hawkes and Webb 1963). The "threshold value" was, therefore, defined as the upper limit of normal background fluctuation, above which an anomalous concentration may be distinguished (Reimann et al. 2005). The geochemical background or the threshold values have importance in environmental sciences, including the soil sciences, in particular in relation to food production and health risk assessment, as they may provide reference values (1) to document the various levels of human-induced transformation of soil quality in relation to parent rock variability, organic matter content, land use, etc.; (2) to assess the relative impact of local contamination sources; (3) to interpret the results of large-scale or long-term monitoring series; and finally (4) to indicate those areas which are free of contamination and thus preferable for high-quality food production (Reimann et al. 2012; Salminen et al. 2005). In many studies, the element concentration in the parent rock horizon $(\mathrm{C})$ of a soil profile has been considered the background for an entire soil profile. Based on this assumption, numerous enrichment or geoaccumulation indexes/factors have been derived (Mazurek et al. 2017; Woszczyk et al. 2018). However, natural pedogenic processes may significantly differentiate the vertical 
distribution of elements throughout the soil profile and may also enhance the content of elements in the topsoil horizons compared to the C layer (Gall et al. 2015; Sterckeman et al. 2006). Moreover, many soils have a lithologic discontinuity at various depths; thus, the bottom part of a soil profile may not represent the parent material for the topsoil (Waroszewski et al. 2015). Therefore, many researchers have argued that the element content in the parent material (C layer) has an indicative function only, whereas the "pedo-geochemical background" for topsoil layers should be separately derived (Baize and Sterckeman 2001; Zhao et al. 2007).

The ability to evaluate the "natural" background for soils is disputed, as soils have been impacted upon by human activity elsewhere since at least the industrial revolution. The term "ambient background" is sometimes suggested to describe the local modified "background" in areas impacted upon by human activity, where the metal concentrations in soils and sediments are slightly elevated, but do not generate any identifiable health or environmental risks (Reimann and Garrett 2005; Mikkonen et al. 2017, 2018). Finally, the term "geochemical baseline" has been suggested to approximate the present ambient background values (Wang et al. 2011). To allow comparisons, the baseline has to be given as a single number ("line") instead of a range of values. Various "baselines" are commonly reported: (1) more restrictive statistical measures such as mean or median metal concentration, and (2) relative (expected) maximum levels, such as mean +2 standard deviations or median +2 median absolute deviations (Gałuszka 2007; Matschullat et al. 2000; Mikkonen et al. 2017).

Several methods are applied to estimate the background values for trace metals in soils and these are sometimes are designated "geochemical" or "statistical" (Matschullat et al. 2000). A "geochemical" attempt refers to pre-industrial archives (such as limnic or marine sediments, overbank and river sediments, cave sediments, or buried soils) that are correlated with a given target surface soil and normalized using respective soil properties, such as $\mathrm{pH}$, texture, or organic matter (Wang et al. 2011). The "statistical" approaches approximate the ambient geochemical baseline based on soil samples collected in each area, where the baseline is required, but where the natural factors may be distinguished from the anthropogenic ones, using, e.g., regression analysis, fractal methods, probability plots, or outlier elimination (Dung et al. 2013; Filzmoser et al. 2005; Matschullat et al. 2000; Reimann et al.
2014; Zhou and Xia 2010). Among the latter methods, the iterative $2 \sigma$ technique, more radical but less robust compared to the other tests, has become relatively popular (Gałuszka 2007; Mikkonen et al. 2017). The technique aims at defining the background by approaching a normal range, where the values beyond the mean $\pm 2 \sigma$ interval are subsequently omitted (Matschullat et al. 2000). Another possible measure of the pollution degree or the natural concentration of trace elements in the topsoil layer is a determination of so-called enrichment factors, which are commonly applied due to their simple calculation (Kowalska et al. 2016, 2018; Mazurek et al. 2017). However, the enrichment factors are strongly criticized because they do not refer to the local or regional background for topsoil layers, and are unsuitable for soils with any lithological discontinuity present in the profile (Reimann and Caritat 2000; Sucharovà et al. 2012).

Chernozems are among the most productive soils in the world due to their thick humus horizon, the fact that they are structural and biologically active and enriched with organic matter and nutrients, as well as their siltloamy texture, which is beneficial for water retention and supply (Novák et al. 2014; Šimansky and Jonczak 2016). Chernozems are recognized in many countries as high-priority soil resources, crucial for national food safety security policy (Chendev et al. 2017; Vysloužilová et al. 2016). Therefore, there is a common social expectation to protect Chernozems against degradation, in particular to safeguard these soils against contamination with trace metals (Kolesnikov et al. 1999; Minkina et al. 2008). The general statement that the concentration of metals in Chernozems is below the action levels, which is known from national soil monitoring programs, is unsatisfactory, as the concentrations desired for high-quality food production are far below the action levels. Unfortunately, the background concentrations of trace metals for Central and Eastern European Chernozems have not been approximated, or approximations have been made based on parent material (loess) only (Kabata-Pendias 2004).

The aim of this study was to estimate the baseline values of trace elements in modern Chernozems developed from loess and to compare these with metal concentrations in the buried Chernozems, as "natural" geochemical background, and then check the following hypotheses: (1) there is no statistically significant difference between the simple statistical measures (mean and median) for background and the refined measures derived using the iterative $2 \sigma$ technique in the 
Chernozems located in uncontaminated areas; (2) baseline values derived for parent material cannot be applied to topsoil layers, i.e., topsoil layers require separate baseline values; (3) the anthropogenic accumulation of trace metals may be distinguished from natural bioaccumulation in the thick humus horizons of Chernozems; and (4) the impact of naturally enhanced background may be distinguished from anthropogenic contamination. The findings will be important for the monitoring of apparent soil contamination with trace metals, and this will provide an appropriate basis for risk assessments for high-quality food production on the world's most valuable soils-Chernozems developed from loess.

\section{Materials and methods}

\section{Area of study}

The study was conducted in SW Poland, within the socalled loess belt extending from Russia and Ukraine, through southern Poland and toward Germany (Fig. 1). Loess covers in SW Poland mainly occur in the Silesian Lowland and the Sudeten Foreland, which are extensive flat regions, more undulating/hilly in the southern part, in the transition to the Sudeten Mountains. The contemporary relief of the region was formed by two/three Pleistocene glaciations and subsequent weathering and denudation processes. Among the glacial deposits in SW Poland, ground (bottom) moraine tills and the glacio-fluvial sands prevail. The last glaciation (Vistulian) was the key period for relief shaping and soil cover development due to widespread loess accumulation (Badura et al. 2013). The thickest loess sediments (more than $3 \mathrm{~m}$ thick), with preserved original sedimentary structures, primarily occur at the borders of the Silesian Lowland. In the central part of the Silesian Lowland and the Sudeten Foreland, the loess cover is shallower, in many places $<1 \mathrm{~m}$ thick, and in some sites it is completely degraded. It cannot be excluded that, during the strong eolian action and formation of loess covers, as well as during the post-sedimentary slope processes, loess may have received admixtures of allogenic Pleistocene or older materials derived, for example, from the local outcrops of granite, gabbro, or serpentinite regoliths (Waroszewski et al. 2018). These types of admixtures may have influenced the texture of some loess patches, and also their mineralogical and chemical compositions, which is particularly likely in the case of serpentinite admixture.

Haplic/Stagnic Luvisols, in mosaics with Eutric Cambisols, Stagnosols, and Gleysols (IUSS Working Group WRB 2015), dominate among the soils developed from loess in SW Poland (Kabala et al. 2015). However, soils with thick humus horizons that satisfy the criteria for a diagnostic mollic/chernic horizon are common or locally prevail in the central part of the region. According to WRB (IUSS Working Group WRB 2015), these soils are classified as Chernozems (well-drained soils) or Phaeozems, often with Gleyic/ Stagnic qualifiers (Labaz et al. 2018).

The area of SW Poland has a mild, temperate climate, with a mean annual air temperature of about $9.5^{\circ} \mathrm{C}$, a mean annual precipitation of 500-650 $\mathrm{mm}$, and a growing season lasting about 225-235 days. The mild climate and fertile silt-loamy soils are conducive to intensive agriculture in this region. Currently, wheat, maize, barley, oilseed rape, and, locally, also sugar beet dominate among the crops (Labaz et al. 2018).

Both the Silesian Lowland and the Sudeten Foreland have been locally occupied by humans since the Paleolithic period and were permanently settled by humans in the Neolithic period (about $6500 \mathrm{BP}$ ) due to their

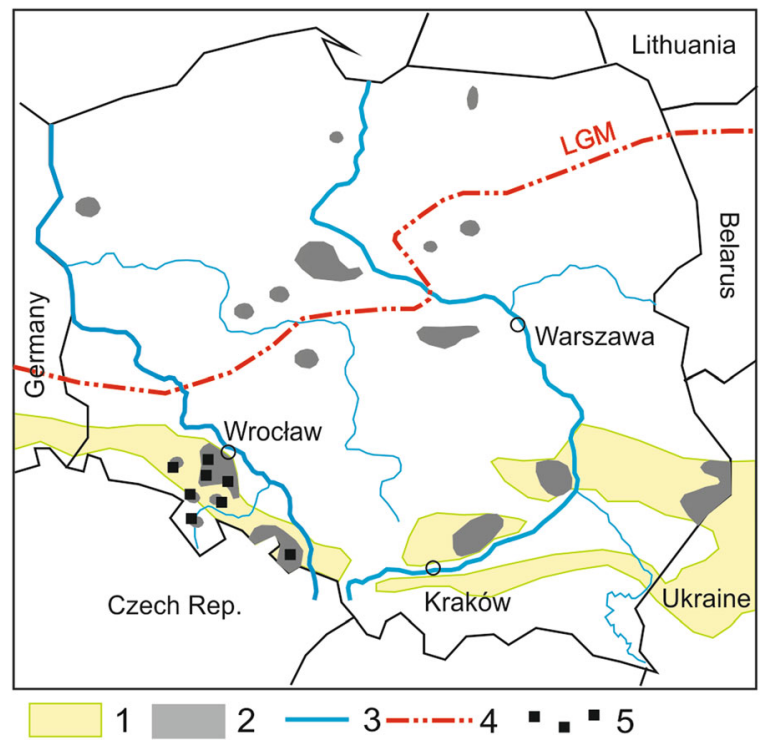

Fig. 1 Distribution of "chernozems" and "black earths" in Poland in relation to loess covers. Soil contours based on Mocek (2015), loess contours based on Jary (2007). Explanation: 1, loess; 2, czernozems (dry) and black earths (moist); 3, main rivers; 4, Last Glacial Maximum (LGM) extend; 5, study site. For interpretation of the references to color in this figure legend, the reader is referred to the web version of this article 
favorable topographical, climatic, and soil conditions. A dense settlement network contributed to the early and extensive deforestation, and the spread of pastures and arable lands.

Field and laboratory methods

The survey was carried out in SW Poland (the Silesian Lowland and the Sudeten Foreland) and included 28 profiles of arable soils classified as Chernozems or Phaeozems (IUSS Working Group WRB 2015). According to the Polish Soil Classification (2011), the soils are Chernozems (welldrained soils) and Black Earths (soils with Gleyic/ Stagnic properties). Soil pits were dug to a depth of $120-160 \mathrm{~cm}$, to reach unaltered parent material. The majority of the soil profiles were developed from thick loess covers $(>200 \mathrm{~cm})$; thus, the soils have homogeneous textures of silt loam throughout the profiles, and the topsoil horizons are developed from the same material as all other genetic horizons (the soils are designated group Ch1 throughout the text and in tables/figures). In 11 soil profiles, the topsoil and subsoil horizons are developed from loess, while the bottom $\mathrm{C}$ horizons are developed from other underlying materials, mostly glaciofluvial sands or glacial loams. Thus, in this group of soils, the material present in the $\mathrm{C}$ horizon cannot be considered the parent material for topsoil layers (soil group designated Ch2). During the laboratory analyses, a particularly high nickel content was found in some soils developed from loess. These soils are located close to an outcrop of serpentinite rocks, regoliths which were probably blown out during the periglacial eolian activity (in the Vistulian period) and were sources of a specific admixture to the silty material, transported by wind from the glacier forefields or from the glacial Odra Great Valley (Badura et al. 2013). These soils were distinguished as a separate group- Ch3. Moreover, the buried Chernozem developed from loess and discovered within the Neolithic earthen barrow (kurgan) in Muszkowice near Henrykow was taken as a "natural reference soil" for the surface Chernozems (Kabala et al. 2015).

Soil samples were collected from all genetic horizons and then, based on their original designation, were technically allocated to groups of horizons to allow reliable statistical analysis. Topsoil arable layers (unified
designation-Ap) that meet the criteria for mollic/ chernic horizons have a similar thickness of about $30 \mathrm{~cm}$ throughout the entire area. The subsurface (nonplowed) part of the humus horizons (unified designation-A2) also meet the criteria for the diagnostic mollic horizon and usually reach the depth of 50-60 cm or more. The transitional horizons are variable and had originally been described as $\mathrm{AC}, \mathrm{AB}, \mathrm{Bw}, \mathrm{Bt}$, or $\mathrm{BC}$, taking into account the pedogenic features. All these transitional horizons were grouped together and given the unified designation $\mathrm{B}$ (to enable statistical analysis). However, two B layers were distinguished in group $\mathrm{Ch} 2$ to reflect the lithological differences between transitional layers in these soils: an upper B1 (silt-loam textures) and an underlying B2 (comprising non-silty textures). The layers of parent material have the unified designation $\mathrm{C}$ (regardless of the presence or absence of carbonates; it was initially proven that the presence of secondary carbonates does not differentiate the $\mathrm{C}$ and $\mathrm{Ck}$ genetic horizons in terms of trace metal content). However, the morphology, texture, and physico-chemical properties of Ap, A1, and B1 horizons in soils developed from loess (silt-loam textured) in groups $\mathrm{Ch} 1$ and $\mathrm{Ch} 2$ are very similar; thus, the horizons were respectively merged for further statistical calculations. Finally, in soil groups Ch1 and Ch2 (Tables 1 and 2), the joint values for Ap, A1, and B1 horizons are displayed, whereas the values for non-silty B2 (in group Ch2) and for $\mathrm{C}$ horizons (silty textured in group $\mathrm{Ch1}$, and non-silty textured in $\mathrm{Ch} 2$ ) are displayed separately. The data for group $\mathrm{Ch} 3$ are given in a separate table, irrespective of their textural similarity to $\mathrm{Ch} 1$, due to the above-described specifically high concentration of nickel (Table 3).

Moreover, samples from the A and C horizons (four samples of each) of a Chernozem buried under the Neolithic kurgan (earthen barrow) discovered near the village Henrykow (central part of the loess belt in SW Poland) have been collected to analyze the concentration of trace metals. Basic physicochemical properties of the central profile of the buried Chernozem were published previously (Kabala et al. 2015).

Soil samples were dried, crushed, and sieved to separate the skeletal fraction $(>2 \mathrm{~mm}$ ), if present. The following analyses were performed on the fine earths ( $<2 \mathrm{~mm}$ ): particle-size distribution using sieves (sand fraction) and the hydrometer method (silt and clay fractions) after sample dispersion with $\mathrm{Na}$ hexametaphosphate; soil $\mathrm{pH}$ in distilled water, 


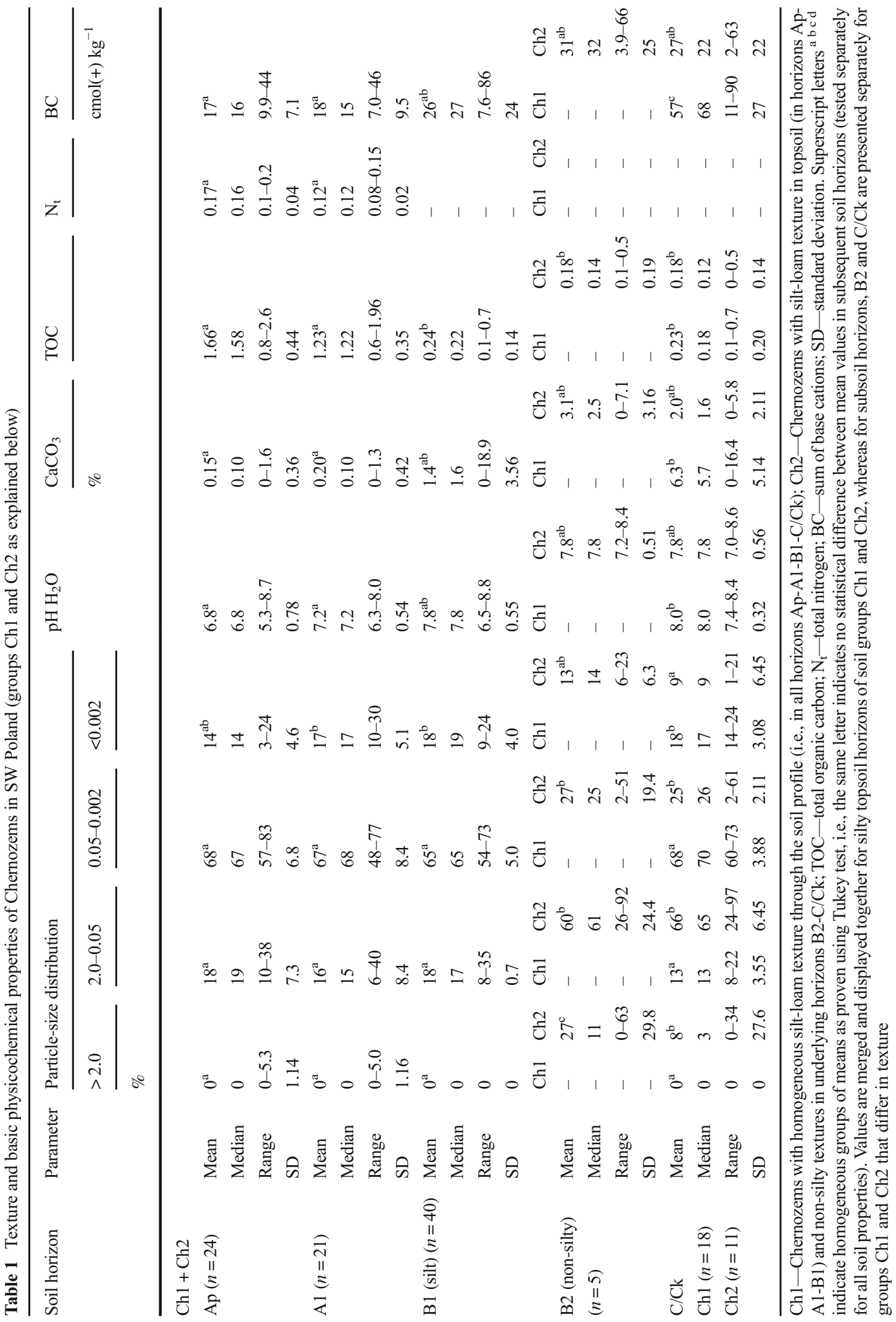




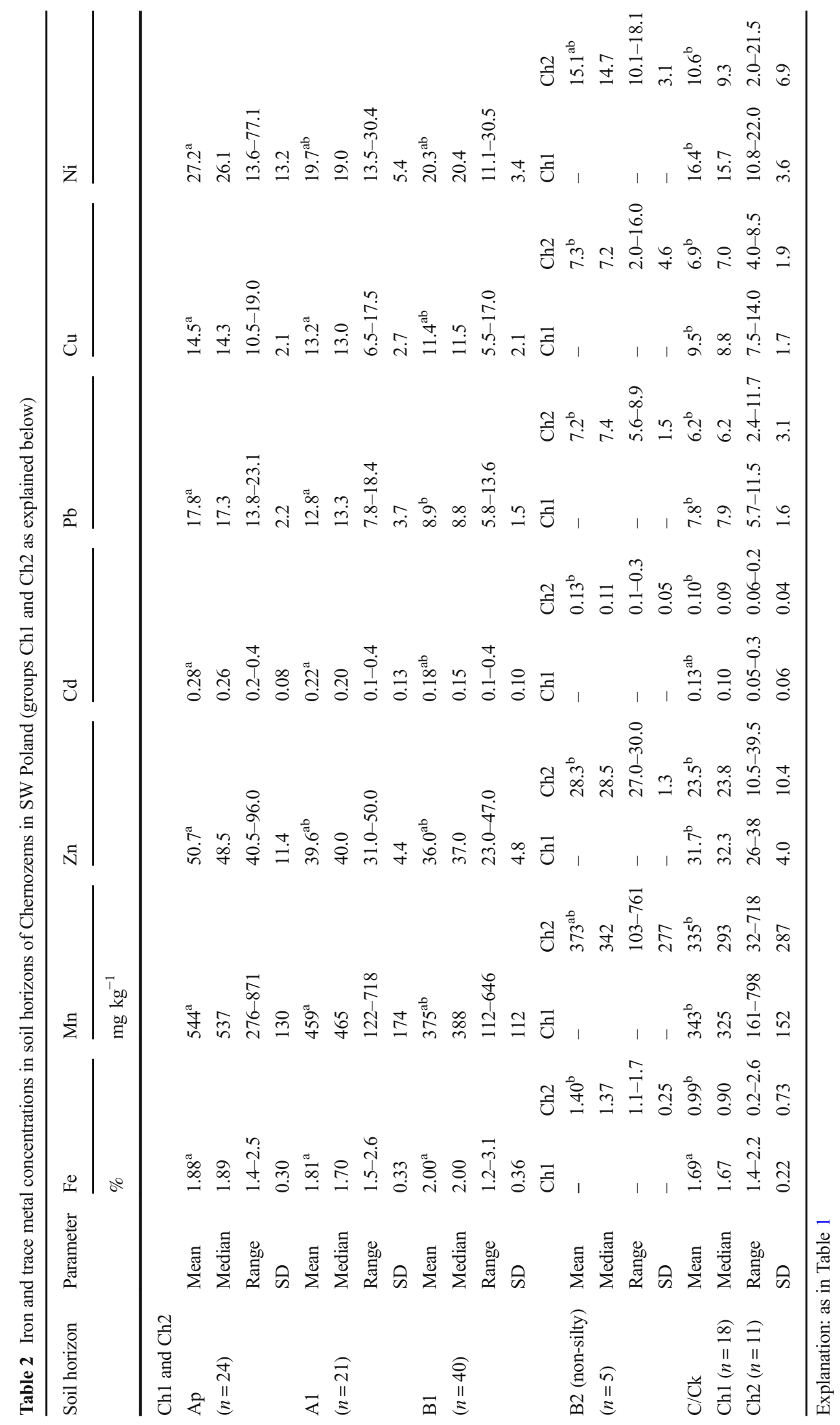




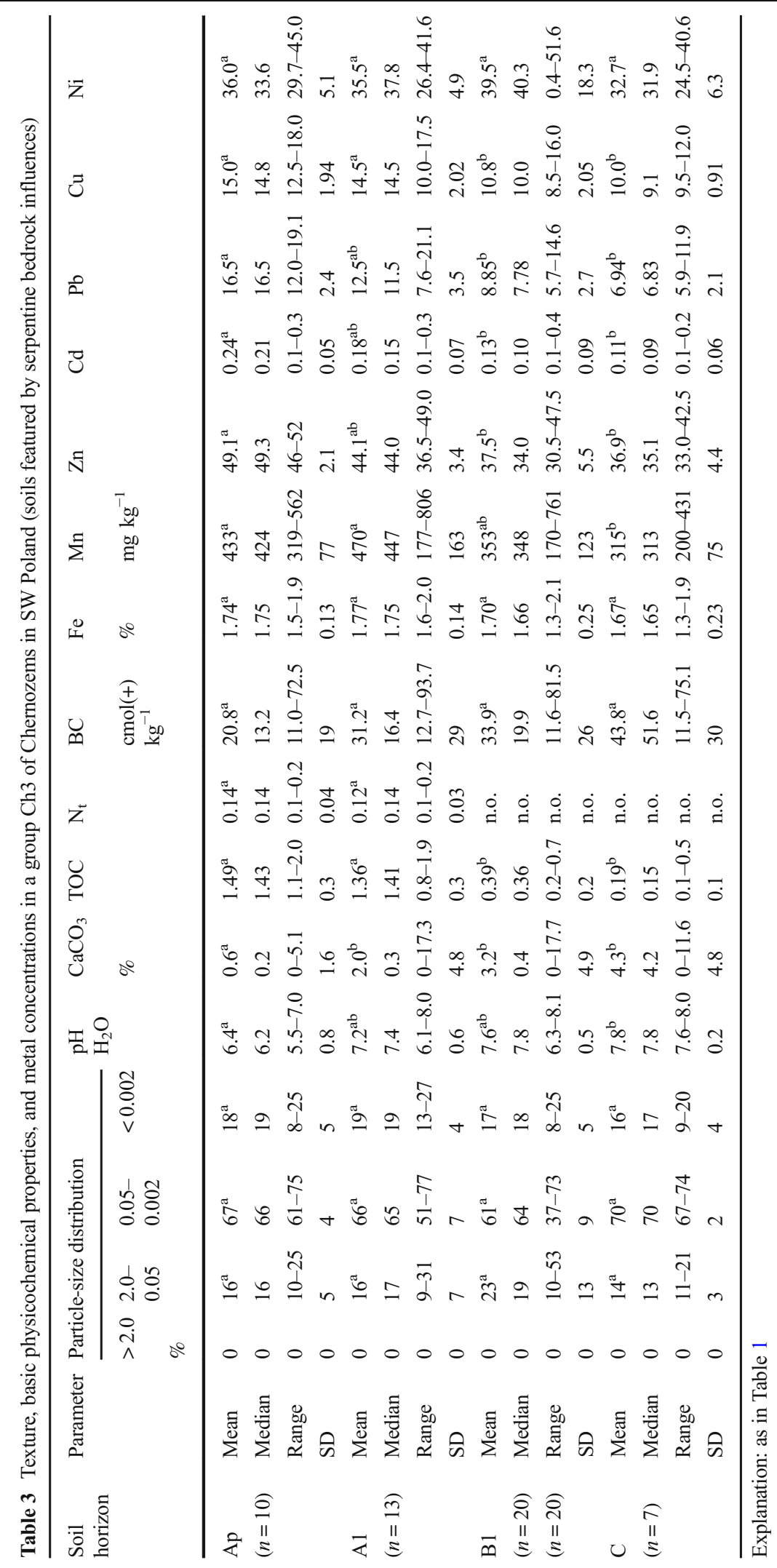


potentiometrically, at the soil/liquid ratio $1: 2.5(\mathrm{v} / \mathrm{v})$; calcium carbonate equivalent $\left(\mathrm{CaCO}_{3}\right)$ by the volumetric method using a Scheibler apparatus (Van Reeuwijk 1992); total organic carbon (TOC) - by dry combustion with spectrometric measurement of the released $\mathrm{CO}_{2}$, using a Ströhlein CS-mat 5500 automated analyzer (after carbonate removal); total nitrogen $\left(\mathrm{N}_{\mathrm{t}}\right)$ - by the Kjeldahl method using a Büchi semiautomated analyzer; and the sum of exchangeable base cations (BC) extracted with $1 \mathrm{M}$ ammonium acetate and analyzed by inductively coupled plasma (ICP-AES Thermo Scientific iCAP 7400). Pseudo-total concentration of iron and trace elements $(\mathrm{Cd}, \mathrm{Cu}, \mathrm{Mn}, \mathrm{Pb}, \mathrm{Zn})$, after extraction with "aqua regia" (concentrated $\mathrm{HCl} / \mathrm{HNO}_{3}, 3: 1$ ), was measured by the ICP-AES technique (Thermo Scientific iCAP 7400) in a certified geochemical laboratory. The accuracy and precision of trace metal measurements were assured by sample analysis in triplicate and regular blank sample controls, as well as involvement of the samples with certified concentrations of metals under analysis (CRM materials).

Basic statistical characteristics, i.e., mean, median, and standard deviation, were extended by Pearson correlation coefficients (at $p<0.05$ ) and principal component analysis (PCA) to test the relationships between metal content and soil properties. The Fisher post hoc test was applied to evaluate the statistical significance of differences between the derived mean values. To approximate the ambient background upper concentration limits (expected maximum), two kinds of threshold were calculated. The first of these was the sum of medians and median absolute deviations (Med + 2MAD). The other method approaches a normal range of data by iterative elimination of outliers, i.e., values beyond the mean \pm 2 standard deviation range, further abbreviated as $x+2 \mathrm{SD}$ (Gałuszka 2007; Matschullat et al. 2000). For particular metals/soil layers, this range was approached in one to five steps. On the other hand, relative indexes of metal concentration in the topsoil were also calculated, i.e., (1) the ratio of metal concentration in the plow layer (Ap) to the directly underlying, non-plowed humus subhorizon (A1), and (2) the modified geoaccumulation index $\left(I_{\text {geo }}\right)$, considered to evaluate topsoil contamination in relation to bedrock geochemistry, but taking into account the pedogenic processes (Kowalska et al. 2016; Müller 1969), and calculated using the following formula:
$I_{\text {geo }}=\log _{2}(A / 1.5 \times C)$,

where:

$I_{\text {geo }}$ geoaccumulation index

A metal concentration in topsoil (plow horizon)

C metal concentration in parent material (C horizon).

All statistical analyses were performed using the Statistica 13 software package (StatSoft Inc.).

\section{Results}

Chernozems where the entire profiles are developed from loess (groups $\mathrm{Ch} 1$ and $\mathrm{Ch} 3$ ) and also the upper layers of Chernozems in the $\mathrm{Ch} 2$ group (Table 1) have typical properties for loess-derived Chernozems in a temperate climate zone. Those soils do not contain a skeletal fraction ( $>2 \mathrm{~mm}$ in diameter), have a dominant silt fraction among the fine earth fractions (66\% on average), a sand content of up to $20 \%$ (mean value), and a clay content of $12-19 \%$ (Tables 1 and 3). This particle-size distribution gives a texture class of silt loam in all layers developed from loess. Other texture classes (sands, less often loams) were only identified in the non-loess B2 and $\mathrm{C}$ horizons, which underlay the loess in the $\mathrm{Ch} 2$ profiles (Table 2). All soils have neutral or near neutral reactions in topsoil and alkaline reactions in subsoil horizons $(\mathrm{pH}$ increases with depth within soil profiles), which is related to the presence of carbonates. The content of calcium carbonate increases with depth, up to 16-19\% (Tables 1 and 3 , which also entails a significant increase in exchangeable base cations with depth, in particular calcium (Figs. 2 and 3). Such a distribution of $\mathrm{pH}$ values and $\mathrm{CaCO}_{\mathrm{s}}$, typical for many Chernozems existing under more humid temperate climates, is related to downward leaching of carbonates that leads to depletion of the topsoil with base cations and its acidification, and then to humus and clay eluviation (Chendev et al. 2017). The soils under study are rich in organic carbon throughout the whole humus horizon $(\mathrm{Ap}+\mathrm{A} 1), 1.24-1.66 \%$ on average, while the organic carbon content decreases significantly in transitional horizons and then in $\mathrm{C}$ horizons (Tables 1 and 3). The high nitrogen content in Ap and A1 horizons (0.12-0.17\% on average), as 


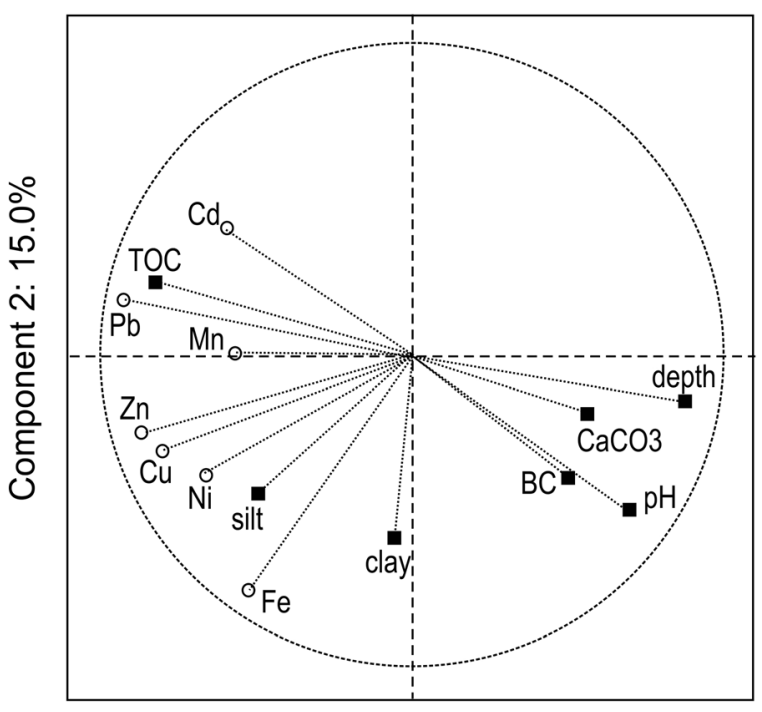

Component 1: $44.8 \%$

Fig. 2 Principal component analysis for the depth in soil profile, basic soil properties, and the concentration of $\mathrm{Fe}$ and trace elements in Chernozems developed from loess (groups $\mathrm{Ch} 1$ and $\mathrm{Ch} 2$, as explained in Table 1). BC, sum of base cations; TOC, total organic carbon; depth, sampling depth in soil profile; clay, fraction $<0.002$; silt, fraction $0.05-0.002$

well as the narrow $\mathrm{C} / \mathrm{N}$ ratio (10-11:1), confirms the high intensity of farming (mineral fertilization), but

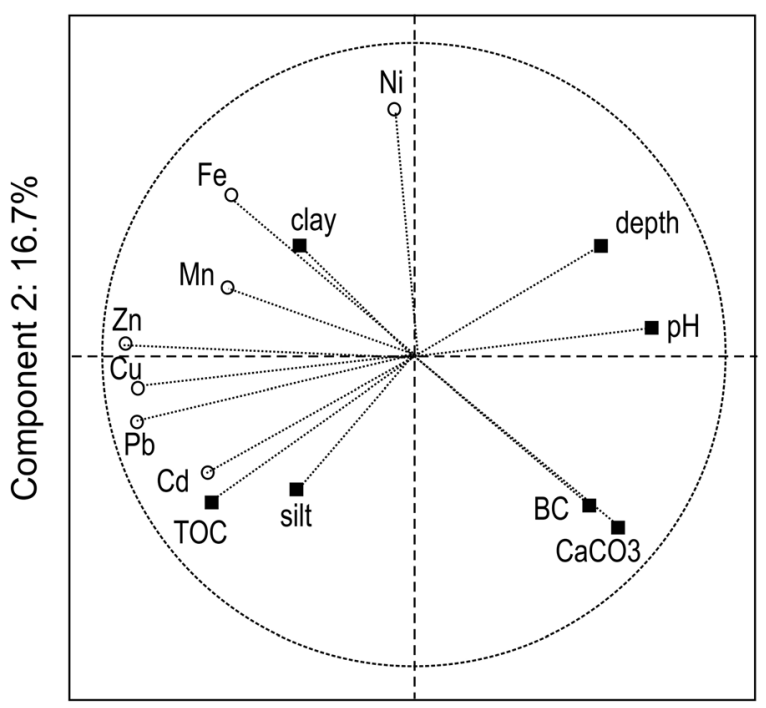

Component 1: $42.9 \%$

Fig. 3 Principal component analysis for the depth in soil profile, basic soil properties, and the concentration of $\mathrm{Fe}$ and trace elements in Chernozems developed from loess with significantly enhanced concentration of nickel (group Ch3 as explained in Table 1). Explanation of abbreviations as in Fig. 2 also high level of biological activity of the topsoil layers.

The median was in most cases slightly lower than the mean concentration of metal in a particular soil layer $(0$ $5 \%$ of relative difference). The median was $10-20 \%$ lower than the mean concentration only in the case of cadmium only (Tables 2 and 3).

The concentration of all elements was the highest in topsoil horizons (Ap and A1) and the lowest in the parent rock layers $(\mathrm{C} / \mathrm{Ck})$, but the vertical differences between soil layers and the statistical significance of these differences are highly variable (Tables 2 and 3). In the homogeneous, loess-derived Chernozems (group Ch1), the least vertical variability was found in the case of iron (no statistically significant differences between the soil horizons). The contents of $\mathrm{Mn}, \mathrm{Zn}, \mathrm{Cu}, \mathrm{Ni}$, and $\mathrm{Cd}$ in the Ap (arable) horizon were 1.5-2 times higher than in the parent rock (C horizon), and in the case of $\mathrm{Pb}-$ more than twice as high (Table 2); and in all cases (but not for Cd), the difference between Ap and C was statistically significant. In group $\mathrm{Ch} 2$, where a lower content of elements in the sandy subsoil horizons is presumed, the ratio of element contents in $\mathrm{Ap}$ and $\mathrm{C}$ horizons exceeded the value of 2 (including Fe), except for $\mathrm{Mn}$, whose concentration also decreased with depth, but to a lesser extent compared to other metals (Table 2).

The mean concentrations of $\mathrm{Fe}, \mathrm{Mn}, \mathrm{Zn}, \mathrm{Pb}$, and $\mathrm{Cu}$ in particular layers of the homogeneous, loess-derived Chernozems of the $\mathrm{Ch} 1$ group did not differ from their concentrations in the respective horizons of the $\mathrm{Ch} 3$ group (Tables 2 and 3). Only the Ni concentrations in all soil horizons of the $\mathrm{Ch} 3$ group are definitely higher than in the Ch1 group, starting from the parent rock horizon, where 32.7 and $16.4 \mathrm{mg} \mathrm{Ni} / \mathrm{kg}$ were found in groups $\mathrm{Ch} 3$ and $\mathrm{Ch} 1$, respectively (Tables 2 and 3). The concentration of $\mathrm{Ni}$ in Chernozem profiles of the $\mathrm{Ch} 3$ group slightly increases toward the topsoil horizons, but the differences are statistically insignificant (Table 3). The vertical distribution of other elements was similar to described in profiles of the $\mathrm{Ch} 1$ group, i.e., Fe concentration did not differ throughout the profile while the concentrations of $\mathrm{Mn}, \mathrm{Zn}, \mathrm{Cd}, \mathrm{Pb}$, and $\mathrm{Cu}$ significantly increased from the parent material layer toward the topsoil (Table 3).

The difference in element concentrations between Ap and A1 layers seems to be crucial for an understanding of the effects of natural bioaccumulation and anthropogenic pollution on the concentration of elements. In the loess-derived Chernozems, the relative differences (the 
ratio $\mathrm{Ap} / \mathrm{A} 1)$ decreased from 1.4 to 1.04 in the following order: $\mathrm{Pb}=\mathrm{Ni}>\mathrm{Zn}>\mathrm{Cd}>\mathrm{Mn}>\mathrm{Cu}>\mathrm{Fe}$ (Table 2). In the $\mathrm{Ch} 3$ group (Table 3), the order is somewhat different $-\mathrm{Cd}=\mathrm{Pb}>\mathrm{Zn}>\mathrm{Cu}>\mathrm{Ni}>\mathrm{Fe}>\mathrm{Mn}$ - and the ratio $\mathrm{Ap} / \mathrm{A} 1$ decreased from 1.3 to 0.92 , respectively.

Statistical analysis, including PCA, verified the strength of the dependence between metal content and soil properties. The relationship between the metal concentration in a particular soil layer and the depth of this layer's location within a soil profile was confirmed; however, the relationship in all soils is very weak in the case of iron (Figs. 2 and 3, Tables 4 and 5), and also insignificant in the case of nickel in the Ch3 group (Fig. 3). Generally, the clay fraction did not affect the metal distribution in the profiles of the Chernozems under study, except for iron (Figs. 2 and 3). The strong relationship between the concentration of trace elements and TOC, confirmed for $\mathrm{Pb}, \mathrm{Cd}, \mathrm{Cu}$, and $\mathrm{Zn}$ (Tables 4 and 5), must be analyzed simultaneously with the similarly strong dependence on the depth in the soil profile (Figs. 2 and 3). The contents of $\mathrm{Zn}, \mathrm{Cu}, \mathrm{Pb}$, and $\mathrm{Mn}$ were strongly mutually correlated in all soils (Tables 4 and 5), which means that the same factors and mechanisms jointly regulate the concentration of the group of trace elements, in particular their concentration in topsoil layers, regardless of the content of TOC and clay fraction (Figs. 2 and 3). The relationship between trace elements and $\mathrm{Fe}$ is weak or statistically insignificant. In "normal" loess-derived Chernozems (group Ch1 and topsoil of group $\mathrm{Ch} 2$ ), the concentration of $\mathrm{Ni}$ is mutually correlated with the other trace elements (Fig. 2), whereas in the $\mathrm{Ch} 3$ group it does not correlate either with the concentrations of other metals, or with the depth in the soil profile, or with the physico-chemical properties of the soil (Fig. 3).

\section{Discussion}

"Raw" versus "refined" baseline values for topsoil layers of Chernozems

Data transformation using the iterative $2 \sigma$ technique, in as many as one to five subsequent steps (if necessary), did not affect the mean concentrations of the trace elements in the distinguished (unified) soil layers, as the differences between the "raw" (not transformed) mean concentrations (Tables 2 and 3 ) and respective "refined" means (Table 6) were not statistically significant in any case. In most cases (Table 7), the "refined" mean was either closer to the "raw" median than to the "raw" mean, or even identical with "raw" median. Such a situation is not unusual and usually attests to the high level of normality of the data distribution (Matschullat et al. 2000) and confirms the appropriate selection of an area to investigate geochemical background. Also, the

Table 4 Coefficients of correlation between depth, soil properties, and concentration of iron and trace metals in Chernozems of SW Poland (calculated for combined groups $\mathrm{Ch} 1+\mathrm{Ch} 2, n=113$ )

\begin{tabular}{|c|c|c|c|c|c|c|c|}
\hline Variable & $\mathrm{Fe}$ & $\mathrm{Mn}$ & $\mathrm{Zn}$ & $\mathrm{Cd}$ & $\mathrm{Pb}$ & $\mathrm{Cu}$ & $\mathrm{Ni}$ \\
\hline Depth & -0.15 & $-0.41^{*}$ & $-0.70^{*}$ & $-0.56^{*}$ & $-0.82 *$ & $-0.63^{*}$ & $-0.47^{*}$ \\
\hline Sand fraction & $-0.55^{*}$ & -0.13 & $-0.37 *$ & $-0.27 *$ & $-0.34 *$ & $-0.46^{*}$ & $-0.27^{*}$ \\
\hline Silt fraction & $0.50 *$ & 0.17 & $0.40 *$ & $0.28 *$ & $0.44 *$ & $0.49 *$ & $0.29^{*}$ \\
\hline Clay fraction & $0.45^{*}$ & -0.07 & 0.07 & 0.09 & -0.15 & 0.14 & 0.06 \\
\hline $\mathrm{pH}$ & -0.02 & $-0.37^{*}$ & $-0.39^{*}$ & $-0.70^{*}$ & $-0.70^{*}$ & $-0.34^{*}$ & $-0.19^{*}$ \\
\hline $\mathrm{CaCO}_{3}$ & $-0.28^{*}$ & $-0.23 *$ & $-0.32^{*}$ & -0.16 & $-0.43^{*}$ & $-0.45^{*}$ & $-0.32^{*}$ \\
\hline TOC & 0.16 & $0.37 *$ & $0.68 *$ & $0.61 *$ & $0.80 *$ & $0.65^{*}$ & $0.39^{*}$ \\
\hline $\mathrm{BC}$ & -0.11 & $-0.23^{*}$ & $-0.23^{*}$ & $-0.27^{*}$ & $-0.40^{*}$ & $-0.31^{*}$ & $-0.22^{*}$ \\
\hline $\mathrm{Fe}$ & & $0.30 *$ & $0.56^{*}$ & -0.05 & $0.31^{*}$ & $0.65^{*}$ & $0.61^{*}$ \\
\hline $\mathrm{Mn}$ & & & $0.45^{*}$ & $0.26^{*}$ & $0.51 *$ & $0.43 *$ & $0.36^{*}$ \\
\hline $\mathrm{Zn}$ & & & & $0.40 *$ & $0.75^{*}$ & $0.70^{*}$ & $0.82^{*}$ \\
\hline $\mathrm{Cd}$ & & & & & $0.59 *$ & $0.20 *$ & 0.17 \\
\hline $\mathrm{Pb}$ & & & & & & $0.68 *$ & $0.53^{*}$ \\
\hline $\mathrm{Cu}$ & & & & & & & $0.49^{*}$ \\
\hline
\end{tabular}

*Statistically significant at $p<0.05$, other explanations - as in Table 1 
Table 5 Coefficients of correlation between depth, soil properties, and concentration of iron and trace metals in Chernozems of SW Poland (group Ch3, $n=46$ )

\begin{tabular}{|c|c|c|c|c|c|c|c|}
\hline Variable & $\mathrm{Fe}$ & $\mathrm{Mn}$ & $\mathrm{Zn}$ & $\mathrm{Cd}$ & $\mathrm{Pb}$ & $\mathrm{Cu}$ & $\mathrm{Ni}$ \\
\hline Depth & -0.10 & -0.25 & $-0.48^{*}$ & $-0.45^{*}$ & $-0.54^{*}$ & $-0.51^{*}$ & 0.13 \\
\hline Sand fraction & $-0.60 *$ & -0.23 & $-0.47 *$ & -0.25 & $-0.44 *$ & $-0.38^{*}$ & $0.48^{*}$ \\
\hline Silt fraction & 0.23 & 0.21 & $0.30 *$ & 0.26 & $0.41 *$ & $0.30 *$ & $-0.65^{*}$ \\
\hline Clay fraction & $0.84 *$ & 0.12 & $0.46^{*}$ & 0.08 & 0.22 & 0.28 & 0.09 \\
\hline $\mathrm{pH}$ & $-0.35^{*}$ & $-0.39 *$ & $-0.60 *$ & $-0.52 *$ & $-0.73 *$ & $-0.49 *$ & 0.01 \\
\hline $\mathrm{CaCO}_{3}$ & $-0.51 *$ & $-0.41 *$ & $-0.55^{*}$ & -0.22 & $-0.50^{*}$ & $-0.50 *$ & $-0.44^{*}$ \\
\hline TOC & 0.04 & $0.45^{*}$ & $0.57 *$ & $0.49 *$ & $0.59 *$ & $0.71 *$ & -0.21 \\
\hline $\mathrm{BC}$ & $-0.41^{*}$ & $-0.40^{*}$ & $-0.43^{*}$ & -0.06 & $-0.43^{*}$ & $-0.34^{*}$ & -0.27 \\
\hline $\mathrm{Fe}$ & & $0.38^{*}$ & $0.62 *$ & 0.14 & $0.37 *$ & $0.43 *$ & 0.23 \\
\hline $\mathrm{Mn}$ & & & $0.52 *$ & 0.22 & $0.37 *$ & 0.61 * & 0.26 \\
\hline $\mathrm{Zn}$ & & & & $0.68^{*}$ & $0.84^{*}$ & $0.86^{*}$ & 0.10 \\
\hline $\mathrm{Cd}$ & & & & & $0.74 *$ & $0.63 *$ & -0.07 \\
\hline $\mathrm{Pb}$ & & & & & & $0.79 *$ & -0.10 \\
\hline $\mathrm{Cu}$ & & & & & & & 0.04 \\
\hline
\end{tabular}

*Statistically significant at $p<0.05$, other explanations - as in Table 1

latter finding confirms the usefulness of the simple characterize the geochemical baseline in appropriately median value, instead of more elaborated indices, to

Table 6 "Refined" mean values ( mean $_{\mathrm{r}}$ ) and threshold values ("ambient background threshold") for iron and trace metals in Chernozems of SW Poland

\begin{tabular}{|c|c|c|c|c|c|c|c|c|c|c|c|c|c|c|c|}
\hline \multirow[t]{3}{*}{ Soil horizon } & \multirow[t]{3}{*}{ Parameter } & \multicolumn{2}{|l|}{$\mathrm{Fe}$} & \multicolumn{2}{|l|}{$\mathrm{Mn}$} & \multicolumn{2}{|l|}{$\mathrm{Zn}$} & \multicolumn{2}{|l|}{$\mathrm{Cd}$} & \multicolumn{2}{|l|}{$\mathrm{Pb}$} & \multicolumn{2}{|l|}{$\mathrm{Cu}$} & \multicolumn{2}{|l|}{$\mathrm{Ni}$} \\
\hline & & \multicolumn{2}{|l|}{$\%$} & \multicolumn{4}{|c|}{$\mathrm{mg} \mathrm{kg}^{-1}$} & & & & & & & & \\
\hline & & Ch1 + & $\mathrm{Ch} 2$ & & & & & & & & & & & & \\
\hline \multirow[t]{4}{*}{ Ap } & $\operatorname{Mean}_{\mathrm{r}}(x)$ & 1.85 & & 541 & & 47.6 & & 0.26 & & 17.3 & & 14.3 & & 24.1 & \\
\hline & Threshold $_{\mathrm{r}}(x+2 \mathrm{SD})$ & 2.40 & & 741 & & 57.7 & & 0.48 & & 20.9 & & 18.2 & & 37.6 & \\
\hline & Threshold $_{\mathrm{m}}(\mathrm{Med}+2 \mathrm{MAD})$ & 2.41 & & 699 & & 58.5 & & 0.46 & & 19.7 & & 16.7 & & 37.2 & \\
\hline & & Ch1 & $\mathrm{Ch} 2$ & Ch1 & $\mathrm{Ch} 2$ & Ch1 & $\mathrm{Ch} 2$ & Ch1 & $\mathrm{Ch} 2$ & Ch1 & $\mathrm{Ch} 2$ & Ch1 & $\mathrm{Ch} 2$ & Ch1 & $\mathrm{Ch} 2$ \\
\hline \multirow[t]{3}{*}{$\mathrm{C} / \mathrm{Ck}$} & $\operatorname{Mean}_{\mathrm{r}}(x)$ & 1.67 & 0.89 & 303 & 345 & 31.7 & 25.0 & 0.12 & 0.10 & 7.55 & 6.25 & 9.21 & 6.90 & 16.4 & 11.5 \\
\hline & Threshold $_{\mathrm{r}}(x+2 \mathrm{SD})$ & 2.05 & 1.93 & 484 & 889 & 39.7 & 47.3 & 0.20 & 0.20 & 10.3 & 12.2 & 11.9 & 10.7 & 23.6 & 24.4 \\
\hline & Threshold $_{\mathrm{m}}(\mathrm{Med}+2 \mathrm{MAD})$ & 2.03 & 1.76 & 491 & 735 & 40.3 & 47.0 & 0.18 & 0.19 & 10.1 & 10.0 & 11.3 & 9.7 & 21.8 & 22.4 \\
\hline \multicolumn{16}{|l|}{ Ch3 } \\
\hline \multirow[t]{3}{*}{ Ap } & $\operatorname{Mean}_{\mathrm{r}}(x)$ & 1.74 & & 433 & & 49.1 & & 0.24 & & 16.5 & & 15.0 & & 36.0 & \\
\hline & Threshold $_{\mathrm{r}}(x+2 \mathrm{SD})$ & 1.99 & & 587 & & 53.3 & & 0.36 & & 21.4 & & 18.9 & & 46.1 & \\
\hline & Threshold $_{\mathrm{m}}(\mathrm{Med}+2 \mathrm{MAD})$ & 1.96 & & 605 & & 48.0 & & 0.31 & & 20.0 & & 15.9 & & 41.0 & \\
\hline \multirow[t]{3}{*}{$\mathrm{C} / \mathrm{Ck}$} & $\operatorname{Mean}_{\mathrm{r}}(x)$ & 1.67 & & 315 & & 36.5 & & 0.11 & & 6.90 & & 9.8 & & 32.7 & \\
\hline & Threshold $_{\mathrm{r}}(x+2 \mathrm{SD})$ & 2.14 & & 466 & & 44.6 & & 0.19 & & 10.9 & & 11.6 & & 45.3 & \\
\hline & Threshold $_{\mathrm{m}}(\mathrm{Med}+2 \mathrm{MAD})$ & 1.95 & & 414 & & 44.5 & & 0.12 & & 9.3 & & 12.5 & & 44.1 & \\
\hline
\end{tabular}

Ch1-Chernozems with homogeneous silt-loam texture through the soil profile; Ch2 - Chernozems with silt-loam texture in topsoil (horizons Ap-A1) and non-silty textures in underlying horizons $\mathrm{C} / \mathrm{Ck}$; $\mathrm{Ch} 3$ - silt-loam textured Chernozems influenced by serpentine bedrock; threshold $\mathrm{r}_{\mathrm{r}}$ - calculated as sum of mean $_{\mathrm{r}}+2$ standard deviations (Matschullat et al. 2000); threshold $\mathrm{m}_{\mathrm{m}}$ - calculated as sum of median +2 median absolute deviations (Mikkonen et al. 2017) 
Table 7 Comparison of median, mean, and "refined" mean for iron and trace metals in Chernozems developed from loess in SW Poland and other reported values (rounded values)

\begin{tabular}{|c|c|c|c|c|c|c|c|c|c|}
\hline Soils & Horizon & Parameter & $\begin{array}{l}\mathrm{Fe} \\
\%\end{array}$ & $\begin{array}{l}\mathrm{Mn} \\
\mathrm{mg} \mathrm{kg}^{-1}\end{array}$ & $\mathrm{Zn}$ & $\mathrm{Cd}$ & $\mathrm{Pb}$ & $\mathrm{Cu}$ & $\mathrm{Ni}$ \\
\hline \multirow{6}{*}{$\begin{array}{l}\text { Chernozems of SW Poland } \\
\text { developed from loess (present study) }\end{array}$} & \multirow[t]{3}{*}{ Ap } & Median & 1.89 & 537 & 49 & 0.26 & 17 & 14 & 26 \\
\hline & & Mean & 1.88 & 544 & 51 & 0.28 & 18 & 15 & 27 \\
\hline & & Mean $_{r}$ & 1.85 & 541 & 48 & 0.26 & 17 & 14 & 24 \\
\hline & \multirow[t]{3}{*}{$\mathrm{C} / \mathrm{Ck}$} & Median & 1.67 & 325 & 32 & 0.10 & 8 & 9 & 16 \\
\hline & & Mean & 1.69 & 343 & 32 & 0.13 & 8 & 10 & 16 \\
\hline & & Mean $_{r}$ & 1.67 & 303 & 32 & 0.12 & 8 & 9 & 16 \\
\hline \multirow{2}{*}{$\begin{array}{l}\text { Buried Chernozem in SW Poland } \\
\text { (Neolithic kurgan; present study) }\end{array}$} & A & \multirow[t]{2}{*}{ Median } & 1.82 & 595 & 44 & 0.13 & 10 & 15 & 19 \\
\hline & $\mathrm{C} / \mathrm{Ck}$ & & 1.61 & 320 & 35 & 0.08 & 8 & 11 & 17 \\
\hline Chernozems (world) ${ }^{1}$ & Ap & Mean & - & 480 & 65 & 0.44 & 23 & 24 & 25 \\
\hline Chernozems (SE Poland) ${ }^{1}$ & Ap & Mean & - & 560 & 62 & 0.38 & 25 & 19 & - \\
\hline Chernozems (Ukraine) ${ }^{2}$ & Ap & Median & - & 648 & 56 & 0.18 & 18 & 16 & 31 \\
\hline
\end{tabular}

${ }^{1}$ Kabata-Pendias (2011)

${ }^{2}$ Klos et al. (2014)

selected areas, where the element concentration has a distribution close to a normal model.

The ("raw") median concentrations of $\mathrm{Zn}, \mathrm{Pb}, \mathrm{Cu}$, and $\mathrm{Ni}$ in the plow layers (Ap) of Chernozems under study are similar or significantly lower than the mean or median concentrations of these elements calculated previously for Chernozems around the world, SE Poland and Ukraine (Table 7). The median for Mn, although higher than the mean value in Chernozems around the Europe, is lower than the Mn contents in Chernozems of SE Poland and Ukraine. In turn, the median for Cd value is significantly higher than the median for Ukrainian Chernozems, but is significantly lower than the mean values for other Chernozems in Poland and around the world. A comparison to these archival mean/median values indicates that the median values determined for trace elements (except $\mathrm{Cd}$ ) in the loess-derived Chernozems in SW Poland are reliable as a geochemical baseline to evaluate contamination in other Chernozems in Europe and around the world. The content of cadmium in the Chernozems of SW Poland, although much lower than the mean $\mathrm{Cd}$ content in global and other Polish Chernozems, is nearly 50\% higher than in Ukrainian Chernozems. This difference is probably related to the long-term and intense fertilization of these soils with Cd-bearing phosphorus fertilizers and other biosolid amendments (McLaughlin et al. 1999), as any other sources of contamination with $\mathrm{Cd}$ are absent in the chernozemic region of SW Poland (Kabala et al.
2015). Nevertheless, the median values found in the present study for $\mathrm{Mn}$ and $\mathrm{Cd}$ are considered a reliable geochemical baseline, at least on a Central European scale (Kabata-Pendias 2011; Kobza et al. 2017; Komárek et al. 2008; Rékási and Filep 2012; Salminen and Tarvainen 1997; Spahić et al. 2018).

The threshold values, interpreted as the ambient background upper concentration limits (i.e., expected maximums), offer a more comprehensive basis for the evaluation of soil contamination, i.e., identification of the concentrations considered significantly higher than the geochemical background (Reimann and Garrett 2005). The thresholds calculated by two different methods - (1) as the sum of median plus two median absolute deviations (Mikkonen et al. 2017) and (2) as the sum of mean plus two standard deviations derived by iterative rejection of outliers (Matschullat et al. 2000) - have generally very similar values for all metals (Table 6). Relatively speaking, the largest differences between these two thresholds were for $\mathrm{Mn}$ (in $\mathrm{Ch} 1+$ $\mathrm{Ch} 2$ soils) and $\mathrm{Cd}$ (in $\mathrm{Ch} 3$ soils). For $\mathrm{Zn}, \mathrm{Pb}, \mathrm{Cd}$, and $\mathrm{Cu}$, both threshold values are close to or lower than the mean concentrations of these metals in topsoil horizons of other Chernozems in SE Poland and around the world (Tables 6 and 7). This confirms the particularly low content of these metals in the soils under study and the applicability of derived baselines (both median values and the aforementioned thresholds) to evaluate the contamination of other Chernozems developed of loess. 
Are the metal concentrations enhanced or "naturally low" in the topsoil layers of Chernozems under investigation?

Reliable, although rarely available, information on the "natural" geochemical background is provided by the presumably uncontaminated soils buried before the industrial era, or even in prehistorical periods. A unique possibility for such a comparison is offered by the complex of Neolithic kurgans (earthen barrows) recently discovered in the loess area near Henrykow, SW Poland (Kabala et al. 2015). The median values in Ap horizons of Chernozems under study in SW Poland are slightly higher, but do not differ statistically from those in the topsoil layer of the buried Chernozem in the case of $\mathrm{Fe}, \mathrm{Zn}, \mathrm{Cu}$, and $\mathrm{Ni}$ (Table 7). In case of $\mathrm{Mn}$, the values in modern Chernozems were found to be even lower than in the buried Chernozem. However, the values for $\mathrm{Pb}$ are $70 \%$ higher, and for $\mathrm{Cd} 100 \%$ higher compared to buried soil (Table 7). Even if this comparison has limited reliability as it includes one buried soil profile only, it confirms expected trends. The similarity of concentrations confirms the lack of contamination in "modern" soils, at least in the case of $\mathrm{Fe}, \mathrm{Mn}, \mathrm{Zn}$, and $\mathrm{Cu}$. These low values also confirm that, even presently in Europe, the "ambient" background may be very similar to or the same as the "natural" background, at least for selected elements and in selected areas, e.g., those free of local industrial sources of contamination (Gałuszka 2007; Migaszewski et al. 2010). The latter seems impossible for $\mathrm{Pb}$ and $\mathrm{Cd}$ due to the very common and worldwide soil contamination with these metals (Adriano 2001; Cannon and Horton 2009; Gorsuch et al. 2006). This cannot be linked to high native $\mathrm{Cd}$ and $\mathrm{Pb}$ concentrations in the parent material, as the loess in the $\mathrm{C}$ horizons of both modern and buried soil contains 2-2.5 times less $\mathrm{Cd}$ and $\mathrm{Pb}$ than the $\mathrm{Ap}$ horizons (Table 7).

Applicability of rock-derived baselines to topsoil horizons

Historically, evaluation of soil contamination started with comparisons to "Clarke values," i.e., mean metal concentrations in the Earth's crust (Kabata-Pendias 2004). Although this approach was abandoned a long time ago, the comparison of metal content in the topsoil to its concentration in the parent material of soil (the socalled $\mathrm{C}$ horizon) is still quite popular in the form of various “enrichment factors" (Kowalska et al. 2016, 2018; Mazurek et al. 2017). This method has been criticized for failing to take into account the natural pedogenic processes that redistribute elements in the soil profile, in particular those related to podzolization and clay illuviation (Reimann and Garrett 2005). However, the approach has probably never been discussed and rejected for slightly leached soil, such as Chernozems, rich in humus and divalent cations that enhance the sorption and stabilization of trace elements.

As shown in the buried natural Chernozem (Table 7), significant differences between $\mathrm{A}$ and $\mathrm{C}$ horizons exist for $\mathrm{Zn}, \mathrm{Mn}$, and $\mathrm{Cd}$ concentrations; a slight difference was noted for $\mathrm{Pb}$, and practically no difference for $\mathrm{Fe}$ and Ni concentrations. This means no difference for the latter elements $(\mathrm{Pb}, \mathrm{Ni}, \mathrm{Fe})$ has developed naturally between topsoil and subsoil horizons in a soil type known for its high biological activity and expected high bioaccumulation rate related to TOC accumulation in the topsoil (Chendev et al. 2017). In turn, the higher concentration of $\mathrm{Zn}, \mathrm{Mn}$, and $\mathrm{Cd}$ in the topsoil of buried Chernozems was due to natural biogeochemical processes (bioaccumulation) and cannot be considered contamination. Therefore, at least the concentrations of $\mathrm{Cd}$, $\mathrm{Mn}$, and $\mathrm{Zn}$ in the parent material (C horizon) of the buried Chernozem cannot serve as a reliable background for the topsoil horizon (a homogeneous silty texture throughout the profile).

A comparison of mean and median values calculated for particular soil horizons of Chernozems in SW Poland (Table 2) indicates statistically significant differences between $\mathrm{C}$ and Ap horizons in the case of all metals, excluding only $\mathrm{Fe}$ (in the homogeneous silty soils, group Ch1, and also group Ch3, excluding $\mathrm{Ni}$ ). As shown above (comparison with buried Chernozem), this difference cannot be considered the result of topsoil contamination alone. Moreover, group $\mathrm{Ch} 2$ represents soils with a lithological discontinuity within the profile, which is relatively common in Central/Northern Europe and North America. Lithological discontinuity (as in the case of loess underlain with glaciofluvial sand) is typically also connected with geochemical discontinuity and makes the direct comparison of the topsoil and subsoil layers unjustifiable. For all metals (including Fe), the mean values in $\mathrm{A}$ and $\mathrm{C}$ horizons of soils in group $\mathrm{Ch} 2$ significantly differ (Table 2). These statements confirm that metal levels in parent rock do not reflect the background values for topsoil horizons in many soils and for many metals; this thus argues for separate baseline 
values for topsoil layers to allow a reliable assessment of topsoil contamination (Reimann et al. 2012; Zhao et al. 2007).

\section{Distribution of metals in Chernozem profiles}

The experimental data indicate relatively low mobility of major and trace elements in Chernozems (Borui et al. 2017; Chernikova et al. 2013; Felix-Henningsen et al. 2010) due to strong metal sorption by humic substances and stabilization of organic complexes under such favorable conditions as neutral soil $\mathrm{pH}$, saturation with divalent cations, and medium-fine texture (Adriano 2001; Minkina et al. 2006, 2008; Šimansky and Jonczak 2016). Thus, it is not the leaching of metals that is the presumed reason for differentiation of the metal concentrations between subsequent horizons of Chernozems, but topsoil bioaccumulation and zooturbation, in particular translocation of humus-rich soil by burrowing animals such as moles and anecic earthworms. Labaz et al. (2018) found that the age of organic matter (in fact - the mean residence time, MRT) increased with depth in thick humus horizons of Chernozems in SW Poland by ca. $350-400$ years per 10 -cm-thick sublayer. This confirms an intense and relatively proportional translocation of "fresh" organic residues from the topsoil down to at least $50-60 \mathrm{~cm}$ (in SW Poland).

Based on the above statement, the concentration of an element should naturally decrease with depth within the thick humus horizon proportionally to the decrease in TOC, if the rate of inflow of the given element to soil is similar to TOC accumulation in the topsoil (Baize and Sterckeman 2001). Potential sources of metal inflow are release from mineral phase by weathering, bio-cycling, and bioaccumulation (uptake by roots from the subsoil and return with biomass), and contamination added with fertilizers or air-borne (Alloway 2013). Metal uptake from subsoil and its return to topsoil by plants could play a role under non-forest vegetation until the humus horizon becomes thicker than dominant plant roots. Moreover, in the case of crop plants, the metal return to soil from biocycling is reduced by its amount removed in the crop yield (Kabata-Pendias 2004).

Such a slight gradual decrease in metal concentration with depth in Chernozems of SW Poland was observed for copper-ca. $10 \%$ decrease in total concentration between subsequent horizons (group Ch1, Table 2). The differences in $\mathrm{Mn}$ and $\mathrm{Zn}$ concentrations between soil horizons are higher (10-22\%), and the highest are differences in $\mathrm{Cd}$ and $\mathrm{Pb}$ concentrations that reach 25$30 \%$ of metal content (in relation to overlying horizon). The Fe and Ni concentrations in soil group Ch1 changed insignificantly or irregularly; thus, the depth trend is uncertain (Table 2) and may be due to the visible (Fig. 2 and Table 4) affinity of these metals to clay fraction, where the maximum was identified in subsurface $\mathrm{B}$ horizons (Table 1). The abrupt decrease in $\mathrm{Pb}$ and $\mathrm{Cd}$ concentrations between $\mathrm{A} 1$ and $\mathrm{B} 1$ horizons (Tables 2 and 3) confirms the particular affinity of these metals to organic matter (Fig. 2).

Chernozems have uniquely thick humus horizons, thicker than the plow layer, where all recent contaminations may concentrate, those from both air-borne pollution and fertilization. Thus, the simple comparison of the metal content in Ap and underlying A2 horizons may indicate the scale of relatively recent metal inflow that is still not "dissolved" by earthworm activity. The ratio of median metal concentration in Ap to A2 horizons, averaged for all soils under study (proportionally to the abundance of soil profiles in the groups $\mathrm{Ch} 1+\mathrm{Ch} 2$ and $\mathrm{Ch} 3$ ), was the lowest for $\mathrm{Fe}, \mathrm{Mn}$, and $\mathrm{Cu}$ (value 1.031.06), intermediate for $\mathrm{Zn}$ and $\mathrm{Ni}$ (1.13-1.16), and the highest for $\mathrm{Cd}$ and $\mathrm{Pb}$ (values 1.35-1.36).

Metal distribution in the soil profile can be assessed with the use of the geoaccumulation index, $I_{\text {geo }}$ (Kowalska et al. 2016; Müller 1969), where those values above 1 are considered to indicate topsoil contamination. The $I_{\text {geo }}$ in the buried (natural) Chernozem has negative values for $\mathrm{Fe}, \mathrm{Ni}, \mathrm{Pb}, \mathrm{Zn}$, and $\mathrm{Cu}$, and positive ones for $\mathrm{Cd}$ and $\mathrm{Mn}$, but no higher than 0.3 (Table 8). In "homogeneous" Chernozems (silty texture throughout the profile) in the present study, Fe still has negative values for $I_{\text {geo }}, \mathrm{Ni}, \mathrm{Zn}, \mathrm{Mn}$, and $\mathrm{Cu}$ have values which are negative or near zero, whereas the $I_{\text {geo }}$ for $\mathrm{Cd}$ and $\mathrm{Pb}$ reached the values of $0.5-0.8$ (Table 8 ).

All the aforementioned relative indices of metal distribution in soil profiles have confirmed that no topsoil enrichment can be concluded in the case of Fe, very little enrichment in case of $\mathrm{Mn}$ and $\mathrm{Cu}$, little enrichment with $\mathrm{Zn}$ and $\mathrm{Ni}$, and significant enrichment in the case of $\mathrm{Cd}$ and $\mathrm{Pb}$.

To provide a contrast, the $I_{\text {geo }}$ values in the $\mathrm{Ch} 2$ soil group should be discussed. Those "heterogeneous" Chernozems have a silty topsoil underlain by a sandy or loamy subsoil of other geological origin (Table 3). The minimum $I_{\text {geo }}$ values started in these soils from 0.3 for $\mathrm{Mn}$; reached $0.4-0.5$ for $\mathrm{Cu}, \mathrm{Zn}$, and $\mathrm{Fe}$; and the level $0.87-0.95$, near the contamination threshold, for 
Table 8 Relative indices of iron and trace metals distribution/accumulation in Chernozems under study

\begin{tabular}{|c|c|c|c|c|c|c|c|}
\hline Parameter/soils & $\mathrm{Fe}$ & $\mathrm{Mn}$ & $\mathrm{Zn}$ & $\mathrm{Cd}$ & $\mathrm{Pb}$ & $\mathrm{Cu}$ & $\mathrm{Ni}$ \\
\hline Ratio of metal concentration in Ap to A2 subhorizons (all soils under study) & 1.03 & 1.05 & 1.16 & 1.35 & 1.36 & 1.06 & 1.13 \\
\hline$I_{\text {geo }}$ for buried (natural), loess-derived Chernozem & -0.41 & 0.31 & -0.25 & 0.12 & -0.26 & -0.14 & -0.42 \\
\hline$I_{\text {geo }}$ for homogeneous, loess-derived Chernozems (group Ch1) & -0.41 & 0.14 & 0.03 & 0.79 & 0.50 & 0.05 & 0.12 \\
\hline$I_{\text {geo }}$ for homogeneous, loess-derived Chernozems (groups Ch3) & -0.50 & -0.15 & -0.09 & 0.64 & 0.69 & 0.12 & -0.51 \\
\hline$I_{\text {geo }}$ for texturally heterogeneous Chernozems (group Ch2) & 0.49 & 0.29 & 0.46 & 0.95 & 0.87 & 0.42 & 0.90 \\
\hline
\end{tabular}

$I_{\text {geo }}$-geoaccumulation index

$\mathrm{Ni}, \mathrm{Cd}$, and $\mathrm{Pb}$ (Table 8). This comparison shows that unreasonable application of $I_{\text {geo }}$ and other indices in texturally differentiated soils may lead to an incorrect evaluation of soil contamination and the overestimation of health and environmental risks (Kowalska et al. 2016; Mazurek et al. 2017).

Specific concentration and distribution of $\mathrm{Ni}-$ an example of a naturally elevated geochemical background

The reason to separate off a number of Chernozem profiles as group $\mathrm{Ch} 3$ was the significantly higher concentration of $\mathrm{Ni}$ in all soil horizons, e.g., the twofold higher $\mathrm{Ni}$ concentration in $\mathrm{C}$ layers of $\mathrm{Ch} 3$ soils as compared do Ch1 soils (Tables 2 and 3, refers both to mean and median values). The lack of any depth trend in $\mathrm{Ni}$ concentration within the soil profile of $\mathrm{Ch} 3$ soils may suggest an internal source of this phenomenon - strong impact of parent material mineralogy (Bonifacio et al. 2010). Although nickel-bearing metamorphic rocks occur in numerous sites in SW Poland, and significant enrichment with $\mathrm{Ni}$ has been identified in soils directly influenced by these rocks (Kierczak et al. 2016; Pedziwiatr et al. 2018), the Chernozems under study are not underlain by serpentinites or other ultramafic rocks and do not adjoin known surface outcrops of these rocks. Ni content in these Chernozems is positively correlated with the sand fraction (Table 5). This is the only case, in the soils under study, where the metal concentration is significantly correlated with the coarse mineral fraction (Tables 4 and 5). The only reasonable explanation for this correlation relates to eolian processes during the Last Glacial Maximum (Vistulian period), i.e., blowing out the fine to medium sand particles from the regoliths of the exposed outcrops of ultramafic rocks, admixing to the other wind-transported particles (blown out from the glacier forefield or old-Odra glacial river valley; Badura et al. 2013), and finally, joint sedimentation as a loess cover. The concentrations of the other elements in the subsoil layer of $\mathrm{Ch} 3$ soils are very similar to those in Ch1 (Tables 2 and 3, and also Table 6) which suggests exceptional enrichment with $\mathrm{Ni}$ alone.

If the elevated $\mathrm{Ni}$ concentration in $\mathrm{Ch} 3$ soils has a natural (i.e., non-anthropogenic) origin, the significantly higher Ni concentrations in both Ap and C layers of the Chernozems in the $\mathrm{Ch} 3$ group (as compared to the respective layers of Chernozems in the $\mathrm{Ch} 1$ group) cannot be considered to represent contamination. As reported by Bonifacio et al. (2010), even much higher amounts of $\mathrm{Ni}$ in soils, but directly related to rock and regolith geochemistry, do not generate damage to plants naturally adapted to specific local geochemistry. Therefore, the refined mean and threshold Ni values (Table 6) could serve as a provisional geochemical baseline for loess-derived Chernozems impacted by ultramafic rock additions, e.g., in risk assessment procedures or analysis of soil monitoring data. It is also possible that the $\mathrm{Ni}$ concentrations may be similarly enhanced in the other soil types considered to be derived from loess (based on their silty texture), but having similar eolian admixtures of Ni-rich materials (Waroszewski et al. 2018). Further studies, including mineralogical investigations of the sand fraction, seem reasonable to explain the sources of enhanced concentrations of $\mathrm{Ni}$ (and possibly of the other trace and rare earth elements) in the soils developed from loess.

\section{Conclusions}

Based on 28 profiles of chernozemic soils developed from loess in an agricultural region in SW Poland presumed to be free of industrial contamination, the geochemical baselines have been derived for $\mathrm{Fe}$ and six common trace metals using the analytical data for four 
standardized soil layers: Ap (plow layer), A1 (non-plow subsurface humus layer), B (transitional), and C (unaltered parent material). The median values for the plow layer (1.89\% for Fe, and 537, 49, 17, 14, and $26 \mathrm{mg} \mathrm{kg}^{-1}$ for $\mathrm{Mn}, \mathrm{Zn}, \mathrm{Pb}, \mathrm{Cu}$, and $\mathrm{Ni}$, respectively) are lower than the mean or median values reported for other Chernozems in SE Poland/Europe/world, and thus may serve as a general geochemical baseline for chernozemic soils developed from loess. The concentration of $\mathrm{Cd}$, although lower than in other Chernozems of Poland and around the world, was significantly higher than in Ukrainian Chernozems and thus may serve as a local baseline only.

The median values for $\mathrm{Fe}, \mathrm{Cu}, \mathrm{Mn}$, and $\mathrm{Zn}$, typically considered the baselines for ambient geochemical background, are very close to the concentrations in the Chernozem buried under the Neolithic kurgan. This means the present concentrations of the above-listed elements in agricultural areas may still be close to their natural geochemical background. However, $\mathrm{Pb}$ and $\mathrm{Cd}$ concentrations were twofold higher than their respective values in the buried natural soil, indicating the scale of general contamination of the topsoil horizons of arable soils with these two metals. The ratio of metal concentration in the plow to underlying non-plowed humus subhorizons increased in the order Fe (value 1.03) < $\mathrm{Mn}=\mathrm{Cu}<\mathrm{Zn}=\mathrm{Ni}<\mathrm{Cd}=\mathrm{Pb}$ (value 1.36) and confirmed a high recent input of $\mathrm{Cd}$ and $\mathrm{Pb}$ to the plowed topsoil horizons of arable soils that greatly exceeds the natural bioaccumulation and zooturbation rates.

Therefore, the values calculated as median plus two median absolute deviations or refined mean plus two standard deviations have the same or similar values (2.4\% for Fe, and 58, 0.46/0.48, 20/21, 17/18, 37/38, and $699 / 741 \mathrm{mg} \mathrm{kg}^{-1}$ for $\mathrm{Zn}, \mathrm{Cd}, \mathrm{Pb}, \mathrm{Cu}, \mathrm{Ni}$, and $\mathrm{Mn}$, respectively) and may serve as threshold values to indicate the loess-derived Chernozems featured by excessive concentrations of these elements, i.e., potentially or apparently contaminated.

Concentrations of elements, both in the surface soils and in the buried Chernozem under study, excluding Fe, are significantly higher in topsoil (plow) layers compared to parent rock (loess in the $\mathrm{C}$ horizon). These findings justify the determination of separate (ambient) background baselines for topsoil horizons and their application in the evaluation of soil contamination scales. Moreover, in soils texturally differentiated, the topsoil and subsoil layers are of different geological origin and different geochemistry. In this case, the common geoaccumulation indexes that compare the element content in topsoil and (false) parent material may significantly overestimate the topsoil contamination.

Underlying or locally outcropped specific bedrocks (e.g., serpentinite rocks) may naturally enhance the total concentration of trace elements in an entire soil profile by the addition of metal-rich regolith particles during the formation of surface covers, e.g., by eolian processes under the periglacial conditions of the Pleistocene period. Such soils are naturally enriched with metals (with nickel in case of serpentinite bedrock), cannot be considered contaminated, and thus require a separate legal treatment, including separate (or individually suited) background baselines for health risk assessment procedures.

Acknowledgments The research was financed by the National Science Centre of Poland (in part from grant Opus 8 No. 2014/15/ B/ST10/04606 and in part from grant Sonata 8 No. 2014/15/D/ ST10/04087).

Open Access This article is distributed under the terms of the Creative Commons Attribution 4.0 International License (http:// creativecommons.org/licenses/by/4.0/), which permits unrestricted use, distribution, and reproduction in any medium, provided you give appropriate credit to the original author(s) and the source, provide a link to the Creative Commons license, and indicate if changes were made.

Publisher's Note Springer Nature remains neutral with regard to jurisdictional claims in published maps and institutional affiliations.

\section{References}

Adriano, D. C. (2001). Trace elements in terrestrial environments: Biogeochemistry, bioavailability and risks of metals (p. 884). New York: Springer-Verlag.

Alloway, B. J. (2013). Sources of heavy metals and metalloids in soils. In Heavy metals in soils (pp. 11-50). Dordrecht: Springer.

Badura, J., Jary, Z., \& Smalley, I. (2013). Sources of loess material for deposits in Poland and parts of Central Europe: the lost Big River. Quaternary International, 296, 15-22.

Baize, D., \& Sterckeman, T. (2001). Of the necessity of knowledge of the natural pedo-geochemical background content in the evaluation of the contamination of soils by trace elements. Science of the Total Environment, 264, 127-139.

Bonifacio, E., Falsone, G., \& Piazza, S. (2010). Linking Ni and Cr concentrations to soil mineralogy: does it help to assess metal contamination when the natural background is high? Journal of Soils and Sediments, 10(8), 1475-1486. 
Borui, L., Hunag, Q., Cai, H., Guo, X., Wang, T., \& Gui, M. (2017). Distribution and speciation of chromium and cadmium in fertilized chernozem. Pedosphere, 27, 1125-1134.

Bruins, M. R., Kapil, S., \& Oehme, F. W. (2000). Microbial resistance to metals in the environment. Ecotoxicology and Environmental Safety, 45, 198-207.

Cannon, W. F., \& Horton, J. D. (2009). Soil geochemical signature of urbanization and industrialization-Chicago, Illinois, USA. Applied Geochemistry, 24(8), 1590-1601.

Chendev, Y. G., Khokhlova, O. S., \& Aleksandrovskii, A. L. (2017). Agrogenic evolution of automorphic chernozems in the forest-steppe zone (Belgorod oblast). Eurasian Soil Science, 50(5), 499-514.

Cheng, Z., Paltseva, A., Li, I., Morin, T., Huot, H., Egendorf, S., \& Grinshtein, M. (2015). Trace metal contamination in New York City garden soils. Soil Science, 180(4/5), 167-174.

Chernikova, O. V., Mazhaiskii, Y. A., Dovgaya, K. B., \& Kurchevskii, S. M. (2013). Balance analysis of heavy metal pollution of podzolized chernozem in a lysimetric experiment. Russian Agricultural Sciences, 39(1), 62-65.

Dung, T. T. T., Cappuyns, V., Swennen, R., \& Phung, N. K. (2013). From geochemical background determination to pollution assessment of heavy metals in sediments and soils. Reviews in Environmental Science and Biotechnology, 12(4), 335-353.

Felix-Henningsen, P., Urushadze, T., Steffens, D., Kalandadze, B., \& Narimanidze, E. (2010). Uptake of heavy metals by food crops from highly-polluted Chernozem-like soils in an irrigation district south of Tbilisi, eastern Georgia. Agronomy Research, 8(1), 781-795.

Filzmoser, P., Garrett, R. G., \& Reimann, C. (2005). Multivariate outlier detection in exploration geochemistry. Computers \& Geosciences, 31(5), 579-587.

Gall, J. E., Boyd, R. S., \& Rajakaruna, N. (2015). Transfer of heavy metals through terrestrial food webs: a review. Environmental Monitoring and Assessment, 187(4), 201.

Gałuszka, A. (2007). A review of geochemical background concepts and an example using data from Poland. Environmental Geology, 52(5), 861-870.

Ghayoraneh, M., \& Qishlaqi, A. (2017). Concentration, distribution and speciation of toxic metals in soils along a transect around a $\mathrm{Zn} / \mathrm{Pb}$ smelter in the northwest of Iran. Journal of Geochemical Exploration, 180, 1-14.

Gorsuch, J., Merrington, G., Welp, G., Dwyer, R., Hennelly, M., \& Schoeters, I. (2006). Assessing risks of metals added to soils in Europe and North America. Environmental toxicology and chemistry, 25(3), 631-634.

Hansda, A., \& Kumar, V. (2017). Influence of Cu fractions on soil microbial activities and risk assessment along $\mathrm{Cu}$ contamination gradient. Catena, 151, 26-33.

Hawkes, H. E., \& Webb, J. S. (1963). Geochemistry in mineral exploration. Soil Science, 95(4), 283.

IUSS Working Group WRB. (2015). World Reference Base for soil resources 2014, update 2015. International soil classification system for naming soil and creating legends for soil maps. Food and Agriculture Organization of the United Nations, Rome.

Jary Z. (2007). Zapis zmian klimatu w górnoplejstoceńskich sekwencjach lessowo-glebowych w Polsce i w zachodniej części Ukrainy. Wrocław. Rozprawy Naukowe Instytutu Geografii i Rozwoju Regionalnego 1. p. 144.
Kabala, C., Karczewska, A., Szopka, K., \& Wilk, J. (2011). Copper, zinc and lead fractions in soils long-term irrigated with municipal wastewater. Communications in Soil Science and Plant Analysis, 42, 905-919.

Kabala, C., Bojko, O., Medynska-Juraszek, A., \& Szczepaniak, A. (2013). Spatial variability and temporal changes in the heavy metal content of soils with a deep furrow-and-ridge microrelief formed by an afforestation plowing. Environmental Monitoring and Assessment, 185(6), 51415150.

Kabala, C., Bekier, J., Bińczycki, T., Bogacz, A., Bojko, O., Cuske, M., Ćwielagg-Piasecka, I., Dębicka, M., Gałka, B., Gersztyn, L., Glina, B., Jamroz, E., Jezierski, P., Karczewska, A., Kaszubkiewicz, J., Kawałko, D., Kierczak, J., Kocowicz, A., Krupski, M., Kusza, G., Łabaz, B., Marzec, M., Medyńska-Juraszek, A., Musztyfaga, E., Perlak, Z., Pędziwiatr, A., Pora, E., Przybył, A., Strączyńska, S., Szopka, K., Tyszka, R., Waroszewski, J., Weber, J., \& Woźniczka, P. (2015). Soils of lower Silesia: Origins, diversity and protection (p. 256). Wrocław: PTG. PTSH.

Kabata-Pendias, A. (2004). Soil-plant transfer of trace elementsan environmental issue. Geoderma, 122(2-4), 143-149.

Kabata-Pendias, A. (2011). Trace elements in soils and plants. 4th edition (p. 520). Boca Raton: CRC press.

Kajka, K., \& Rutkowska, B. (2018). Accumulation of selected heavy metals in soils and common dandelion (Taraxacum officinale) near a road with high traffic intensity. Soil Science Annual, 69(1), 11-16.

Karak, T., Bora, K., Paul, R. K., Das, S., Khare, P., Dutta, A. K., \& Boruah, R. K. (2017). Paradigm shift of contamination risk of six heavy metals in tea (Camellia sinensis L.) growing soil: a new approach influenced by inorganic and organic amendments. Journal of Hazardous Materials, 338, 250-264.

Karczewska, A., \& Kabala, C. (2017). Environmental risk assessment as a new basis for evaluation of soil contamination in Polish law. Soil Science Annual, 68(2), 67-80.

Kierczak, J., Pedziwiatr, A., Waroszewski, J., \& Modelska, M. (2016). Mobility of $\mathrm{Ni}, \mathrm{Cr}$ and $\mathrm{Co}$ in serpentine soils derived on various ultrabasic bedrocks under temperate climate. Geoderma, 268, 78-91.

Klos, V., Birke, M., Akinfiev, G., \& Amashukeli, Y. (2014). Geochemical characteristics of Ukrainian soil using landscape-geochemical regionalisation based on the GEMAS data. In C. Reimann, M. Birke, A. Demetriades, P. Filzmoser, \& P. O'Connor (Eds.), Chemistry of Europe's agricultural soils. Part B. general background information and further analysis of the GEMAS data set (pp. 253-270). Hannover: Bundesanstalt fuer Geowissenschaften umd Rohstoffe, Schweizerbart.

Kobza, J., Barančíková, G., Makovníková, J., Pálka, B., Styk, J., \& Šráň, M. (2017). Current state and development of land degradation processes based on soil monitoring in Slovakia. Agriculture, 63(2), 74-85.

Kolesnikov, S. I., Kazeev, K. S., \& Val'kov, V. F. (1999). The effect of heavy metal contamination on the microbial system in chernozem. Eurasian Soil Science, 32(4), 459-465.

Komárek, M., Száková, J., Rohošková, M., Javorská, H., Chrastný, V., \& Balík, J. (2008). Copper contamination of vineyard soils from small wine producers: a case study from the Czech Republic. Geoderma, 147(1-2), 16-22. 
Komorowski, A., \& Szulc, W. (2017). Impact of traffic routes on the content of trace elements in soils in Warsaw agglomeration. Soil Science Annual, 68(2), 87-92.

Kowalska, J., Mazurek, R., Gąsiorek, M., Setlak, M., Zaleski, T., \& Waroszewski, J. (2016). Soil pollution indices conditioned by medieval metallurgical activity. A case study from Kraków (Poland). Environmental Pollution, 218, 10231036.

Kowalska J.B., Mazurek R., Gąsiarek M., Zalewski T. (2018). Pollution indices as useful tools for the comprehensive evaluation of the degree of soil contamination-A review. Environmental Geochemistry and Health, 40(6), 395-2420.

Labaz, B., Musztyfaga, E., Waroszewski, J., Bogacz, A., Jezierski, P., \& Kabala, C. (2018). Landscape-related transformation and differentiation of Chernozems - catenary approach in the Silesian lowland, SW Poland. Catena, 161, 63-76.

Maliszewska-Kordybach, B., \& Smreczak, B. (2003). Habitat function of agricultural soils as affected by heavy metals and polycyclic aromatic hydrocarbons contamination. Environment International, 28(8), 719-728.

Matschullat, J., Ottenstein, R., \& Reimann, C. (2000). Geochemical background-can we calculate it? Environmental Geology, 39(9), 990-1000.

Mazurek, R., Kowalska, J., Gąsiorek, M., Zadrożny, P., Józefowska, A., Zaleski, T., \& Orłowska, K. (2017). Assessment of heavy metals contamination in surface layers of Roztocze National Park forest soils (SE Poland) by indices of pollution. Chemosphere, 168, 839-850.

McLaughlin, M. J., Parker, D. R., \& Clarke, J. M. (1999). Metals and micronutrients-food safety issues. Field Crops Research, 60(1-2), 143-163.

Medynska-Juraszek, A., \& Kabala, C. (2012). Heavy metal pollution of forest soils affected by the copper industry. Journal of Elementology, 17(3), 441-451.

Mehr, M. R., Keshavarzi, B., Moore, F., Sharifi, R., Lahijanzadeh, A., \& Kermani, M. (2017). Distribution, source identification and health risk assessment of soil heavy metals in urban areas of Isfahan province, Iran. Journal of African Earth Sciences, 132, 16-26.

Migaszewski, Z. M., Gałuszka, A., \& Pasławski, P. (2010). Baseline element concentrations in soils and plant bioindicators of selected national parks of Poland. Geological Quarterly, 48(4), 383-394.

Mikkonen, H. G., Clarke, B. O., Dasika, R., Wallis, C. J., \& Reichman, S. M. (2017). Assessment of ambient background concentrations of elements in soil using combined survey and open-source data. Science of the Total Environment, 580, $1410-1420$.

Mikkonen, H. G., Dasika, R., Drake, J. A., Wallis, C. J., Clarke, B. O., \& Reichman, S. M. (2018). Evaluation of environmental and anthropogenic influences on ambient background metal and metalloid concentrations in soil. Science of the Total Environment, 624, 599-610.

Minkina, T. M., Motuzova, G. V., \& Nazarenko, O. G. (2006). Interaction of heavy metals with the organic matter of an ordinary chernozem. Eurasian Soil Science, 39(7), 720-726.

Minkina, T. M., Motuzova, G. V., Nazarenko, O. G., Kryshchenko, V. S., \& Mandzhieva, S. S. (2008). Forms of heavy metal compounds in soils of the steppe zone. Eurasian Soil Science, 41(7), 708-716.
Mocek A. (2015). Gleboznawstwo - Soil Science. Wydawnictwo Naukowe PWN. pp. 464.

Müller, G. (1969). Index of geoaccumulation in sediments of the Rhine River. Geojournal, 2, 108-118.

Novák, T. J., Incze, J., Spohn, M., Glina, B., \& Giani, L. (2014). Soil and vegetation transformation in abandoned vineyards of the Tokaj Nagy-Hill, Hungary. Catena, 123, 88-98.

Orzechowski, M., \& Smólczynski, S. (2010). Content of Ca, Mg, $\mathrm{Na}, \mathrm{K}, \mathrm{P}, \mathrm{Fe}, \mathrm{Mn}, \mathrm{Zn}, \mathrm{Cu}$ in soils developed from the Holocene deposits in North-Eastern Poland. Journal of Elementology, 15(1), 149-159.

Pan, J., Plant, J. A., Voulvoulis, N., Oates, C. J., \& Ihlenfeld, C. (2010). Cadmium levels in Europe: implications for human health. Environmental Geochemistry and Health, 32(1), 112.

Pędziwiatr, A., Kierczak, J., Waroszewski, J., Ratié, G., Quantin, C., \& Ponzevera, E. (2018). Rock-type control of Ni, Cr, and Co phytoavailability in ultramafic soils. Plant and Soil, 423(1-2), 339-362.

Polish Soil Classification. (2011). Roczniki Gleboznawcze-Soil Science Annual 62 (3), pp. 193.

Reganold, J. P., \& Wachter, J. M. (2016). Organic agriculture in the twenty-first century. Nature Plants, 2(2), 15221.

Reimann, C., \& Caritat, P. D. (2000). Intrinsic flaws of element enrichment factors (EFs) in environmental geochemistry. Environmental Science \& Technology, 34(24), 5084-5091.

Reimann, C., \& Garrett, R. G. (2005). Geochemical backgroundconcept and reality. Science of the Total Environment, 350(13), 12-27.

Reimann, C., Filzmoser, P., \& Garrett, R. G. (2005). Background and threshold: critical comparison of methods of determination. Science of the Total Environment, 346(1-3), 1-16.

Reimann, C., Flem, B., Fabian, K., Birke, M., Ladenberger, A., Négrel, P., \& Hoogewerff, J. (2012). Lead and lead isotopes in agricultural soils of Europe- the continental perspective. Applied Geochemistry, 27(3), 532-542.

Reimann, C., Birke, M., Demetriades, A., Filzmoser, P., \& O'Connor, P. (2014). Chemistry of Europe's agricultural soils. Part B. general background information and further analysis of the GEMAS data set (p. 349). Hannover: Bundesanstalt fuer Geowissenschaften umd Rohstoffe, Schweizerbart.

Rékási, M., \& Filep, T. (2012). Fractions and background concentrations of potentially toxic elements in Hungarian surface soils. Environmental Monitoring and Assessment, 184(12), 7461-7471.

Salminen, R., \& Tarvainen, T. (1997). The problem of defining geochemical baselines. A case study of selected elements and geological materials in Finland. Journal of Geochemical Exploration, 60(1), 91-98.

Salminen, R., Plant, J. A., Reeder, S., \& Salminen, R. (2005). Geochemical atlas of Europe. Part 1. Background information, methodology and maps (pp. 67-79). Espoo: Geological Survey of Finland.

Schaecke, W., Tanneberg, H., \& Schilling, G. (2002). Behavior of heavy metals from sewage sludge in a Chernozem of the dry belt in Saxony-Anhalt/Germany. Journal of Plant Nutrition and Soil Science, 165(5), 609-617.

Seregin, I. V., \& Ivanov, V. B. (2001). Physiological aspects of cadmium and lead toxic effects on higher plants. Russian Journal of Plant Physiology, 48(4), 523-544. 
Šimansky, V., \& Jonczak, J. (2016). Water-stable aggregates as a key element in the stabilization of soil organic matter in the Chernozems. Carpathian Journal of Earth and Environmental Sciences, 11(2), 511-517.

Spahić, M. P., Sakan, S., Cvetković, Ž., Tančić, P., Trifković, J., Nikić, Z., \& Manojlović, D. (2018). Assessment of contamination, environmental risk, and origin of heavy metals in soils surrounding industrial facilities in Vojvodina, Serbia. Environmental Monitoring and Assessment, 190(4), 208.

Sterckeman, T., Douay, F., Baize, D., Fourrier, H., Proix, N., Schvartz, C., \& Carignan, J. (2006). Trace element distributions in soils developed in loess deposits from northern France. European Journal of Soil Science, 57(3), 392-410.

Sucharovà, J., Suchara, I., Hola, M., Marikova, S., Reimann, C., Boyd, R., Filzmoser, P., \& Englmaier, P. (2012). Top-/bottom-soil ratios and enrichment factors: what do they really show? Applied Geochemistry, 27(1), 138-145.

Tyszka, R., Pietranik, A., Kierczak, J., Ettler, V., Mihaljevič, M., \& Medyńska-Juraszek, A. (2016). Lead isotopes and heavy minerals analyzed as tools to understand the distribution of lead and other potentially toxic elements in soils contaminated by cu smelting (Legnica, Poland). Environmental Science and Pollution Research, 23, 24350-24363.

US EPA Interstate Technology and Regulatory Council. (2008). Use of risk assessment in Management of Contaminated Sites. RISK-2. Washington, DC: Risk Assessment Resources Team.

Van Reeuwijk, L. P. (1992). Procedures for soil analysis. International Soil Reference and Information Centre, Technical Paper 19, Wageningen, The Netherlands, pp. 100.

Vodyanitskii, Y. N. (2013). Contamination of soils with heavy metals and metalloids and its ecological hazard (analytic review). Eurasian Soil Science, 46(7), 793-801.
Vysloužilová, B., Ertlen, D., Schwartz, D., \& Šefrna, L. (2016). Chernozem. From concept to classification: a review. AUC Geographica, 51, 85-95.

Wang, Z., Darilek, J. L., Zhao, Y., Huang, B., \& Sun, W. (2011). Defining soil geochemical baselines at small scales using geochemical common factors and soil organic matter as normalizers. Journal of Soils and Sediments, 11(1), 3-14.

Waroszewski, J., Kabala, C., \& Jezierski, P. (2015). Relief-induced soil differentiation at the sandstone-mudstone contact in the Stołowe Mountains, SW Poland. Zeitschrift für Geomorphologie, Supplementary, 59(1), 209-224.

Waroszewski, J., Sprafke, T., Kabala, C., Musztyfaga, E., Łabaz, B., \& Woźniczka, P. (2018). Aeolian silt contribution to soils on mountain slopes (Mt. Ślęża, Southwest Poland). Quaternary Research, 89(3), 702-717.

Wcisło, E., Ioven, D., Kucharski, R., \& Szdzuj, J. (2002). Human health risk assessment case study: an abandoned metal smelter site in Poland. Chemosphere, 47, 507-515.

Woszczyk, M., Spychalski, W., \& Boluspaeva, L. (2018). Trace metal $(\mathrm{Cd}, \mathrm{Cu}, \mathrm{Pb}, \mathrm{Zn})$ fractionation in urban-industrial soils of Ust-Kamenogorsk (Oskemen), Kazakhstan - implications for the assessment of environmental quality. Environmental Monitoring and Assessment, 190(6), 362.

Zhao, F. J., McGrath, S. P., \& Merrington, G. (2007). Estimates of ambient background concentrations of trace metals in soils for risk assessment. Environmental Pollution, 148(1), 221-229.

Zhou, X., \& Xia, B. (2010). Defining and modelling the soil geochemical background of heavy metals from the Hengshi River watershed (southern China): Integrating EDA, stochastic simulation and magnetic parameters. Journal of Hazardous Materials, 180(1-3), 542-551. 